\title{
¿Snowfall-Rate Retrieval for K- and W-Band Radar Measurements Designed in Hyytiälä, Finland, and Tested at Ny-Ålesund, Svalbard, Norway
}

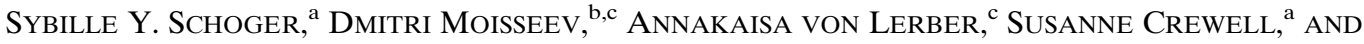 \\ KERSTIN EBELL ${ }^{\mathrm{a}}$ \\ ${ }^{\mathrm{a}}$ Institute for Geophysics and Meteorology, University of Cologne, Cologne, Germany \\ ${ }^{\mathrm{b}}$ Institute for Atmospheric and Earth System Research/Physics, Faculty of Science, University of Helsinki, Finland \\ ${ }^{\mathrm{c}}$ Finnish Meteorological Institute, Helsinki, Finland
}

(Manuscript received 22 April 2020, in final form 4 December 2020)

\begin{abstract}
Two power-law relations linking equivalent radar reflectivity factor $Z_{e}$ and snowfall rate $S$ are derived for a K-band Micro Rain Radar (MRR) and for a W-band cloud radar. For the development of these $Z_{e}-S$ relationships, a dataset of calculated and measured variables is used. Surface-based video-disdrometer measurements were collected during snowfall events over five winters at the high-latitude site in Hyytiälä, Finland. The data from 2014 to 2018 include particle size distributions (PSD) and their fall velocities, from which snowflake masses were derived. The K- and W-band $Z_{e}$ values are computed using these surface-based observations and snowflake scattering properties as provided by T-matrix and single-particle scattering tables, respectively. The uncertainty analysis shows that the K-band snowfall-rate estimation is significantly improved by including the intercept parameter $N_{0}$ of the PSD calculated from concurrent disdrometer measurements. If $N_{0}$ is used to adjust the prefactor of the $Z_{e}-S$ relationship, the RMSE of the snowfall-rate estimate can be reduced from 0.37 to around $0.11 \mathrm{~mm} \mathrm{~h}^{-1}$. For W-band radar, a $Z_{e}-S$ relationship with constant parameters for all available snow events shows a similar uncertainty when compared with the method that includes the PSD intercept parameter. To demonstrate the performance of the proposed $Z_{e}-S$ relationships, they are applied to measurements of the MRR and the W-band microwave radar for Arctic clouds at the Arctic research base operated by the German Alfred Wegener Institute Helmholtz Centre for Polar and Marine Research (AWI) and the French Polar Institute Paul Emile Victor (IPEV) (AWIPEV) in Ny-Ålesund, Svalbard, Norway. The resulting snowfall-rate estimates show good agreement with in situ snowfall observations while other $Z_{e}-S$ relationships from literature reveal larger differences.
\end{abstract}

KEYWORDS: Arctic; Precipitation; Snow; Snowfall; Radars/Radar observations; Remote sensing

\section{Introduction}

Solid precipitation and its deposition as snow are of great importance for Earth's energy budget and its hydrological cycle. Especially in the Arctic and already at latitudes higher than $60^{\circ} \mathrm{N}$, snowfall is the predominant precipitation type (Levizzani et al. 2011). We know today that temperatures are rising about 2 times faster in the Arctic than anywhere else on Earth due to global warming (IPCC 2007; Serreze and Barry 2011), known as Arctic amplification. This has a great effect on the hydrological cycle and the transformation of precipitation from mainly solid to more liquid precipitation (López-Moreno et al. 2016; Maturilli et al. 2013). Thus, to observe the effects of climate change better, there is an urgent need to monitor longterm snowfall at the northern high latitudes. However, especially in the Arctic, a ground-based observational precipitation network is scarce and the environmental conditions such as weather and orography are harsh for instrumentation (Førland et al. 2011). Additionally, the measurement of snow particles and the identification of the true amount of snow at the ground is a challenging task due to the complex and strongly variable

¿ Denotes content that is immediately available upon publication as open access.

Corresponding author: Kerstin Ebell, kebell@meteo.uni-koeln.de microphysical properties of snow and ice crystals. For classical precipitation gauges, the liquid equivalent amount of snow is a direct measure; however, it is prone to large uncertainties especially in windy conditions (Rasmussen et al. 2012) and still only a point information of precipitation. Radar provides more information on the spatial distribution of precipitation, but snowfall rate $\left(S ; \mathrm{mm} \mathrm{h}^{-1}\right)$ is an indirect measure and has to be obtained from the equivalent radar reflectivity (further, often just reflectivity) $\left(Z_{e} ; \mathrm{mm}^{6} \mathrm{~m}^{-3}\right.$ or $\left.\mathrm{dB} Z\right)$. The relationship between $Z_{e}$ and $S$ is traditionally retrieved via the power law $Z_{e}=a_{\mathrm{zs}} S^{b_{\mathrm{zs}}}$. The prefactor $a_{\mathrm{zs}}$ has the unit of $\mathrm{mm}^{6-b_{\mathrm{zs}}} \mathrm{h}^{b_{\mathrm{zs}}} \mathrm{m}^{-3}$ (in later sections omitted for better readability), and the exponent $b_{\mathrm{zs}}$ is unitless.

More than 60 years of research have yielded many publications on different $Z_{e}-S$ relationship parameters (e.g., Langille and Thain 1951; Carlson and Marshall 1972; Fujiyoshi et al. 1990; Rasmussen et al. 2003; Huang et al. 2010; von Lerber et al. 2017), because for each snow event, each measurement location, and each radar wavelength used the parameters of the $Z_{e}-S$ relationship differ significantly. Radar snowfall-rate research began by analyzing reflectivity measurements from weather radars that measure at centimeter wavelengths. Many of the $Z_{e}-S$ relationships for weather radars have been determined with the prefactor $a_{\mathrm{zs}}$ ranging, for example, between values of 160 and 3300 and $b_{\mathrm{zs}}$ between 1.5 and 2.2, which are summarized by Rasmussen et al. (2003). In the 1980s, Lhermitte $(1987,1988)$ has pioneered the investigation 
of nonprecipitating clouds from millimeter wavelength radars. Kollias et al. (2007) argued that these radars can also be used for precipitation even though attenuation is significant. For solid precipitation, especially dry snowfall, however, attenuation for W-band radar is small relative to rainfall (Matrosov et al. 2008). The prefactor value range for the $Z_{e}-S$ relationship reduces by an order of magnitude when using millimeter wavelength radars instead of weather radars. For example, the range is only between 2.19 and 313.29 for the prefactor and 0.8 and 1.85 for the exponent (Matrosov 2007; Kulie and Bennartz 2009; Souverijns et al. 2017, hereinafter S17).

In 2006, the satellite CloudSat (Stephens et al. 2002) was launched with the $94-\mathrm{GHz}$ (3.19 mm wavelength) Cloud Profiling Radar (CPR) that provides operational near-global active snowfall measurements, to this day. Especially over the polar regions, this measure is unique and important. However, the expected lifetime is already exceeded (Stephens et al. 2018) and the so-called blind zone in the lowest $1200 \mathrm{~m}$ leads both to misses and false alarms in surface snowfall events with an average precipitation underestimation of around 10\% (Maahn et al. 2014).

The motivation and aim of this study is to operationally retrieve snowfall rates from a ground-based radar at highlatitude observational sites. The robust and low-cost Micro Rain Radar (MRR) is frequently used at different sites around the globe, however, just recently installed for operational use in the Arctic at the research base operated by the German Alfred Wegener Institute Helmholtz Centre for Polar and Marine Research (AWI) and the French Polar Institute Paul Emile Victor (IPEV) (AWIPEV) at Ny-Ålesund, Svalbard, Norway. With the improved processing method for snow observations proposed by Maahn and Kollias (2012), the MRR has emerged as a promising device for autonomous snowfall monitoring and is used, for example, already in Antarctica since 2010 (S17).

To retrieve parameters for the $Z_{e}-S$ relationship, two different approaches exist. One approach connects measured $Z_{e}$ to ground-based in situ observations. The latter are used from either gauges (Fujiyoshi et al. 1990) or disdrometers (Huang et al. 2010) to obtain constant parameters over a longer time period or for a set of snow events. Another approach is an analytical retrieval of the snowfall rate considering the particle size distribution (PSD) of the snow particles, which can be measured or taken from literature (Heymsfield et al. 2016; von Lerber et al. 2017).

Within this paper, we use both approaches to retrieve $Z_{e}-S$ relationships for two different radar frequencies: for the MRR, which measures at $24 \mathrm{GHz}$ in the $\mathrm{K}$ band, and for a W-band radar, that measures at the same frequency as the CloudSat CPR. To calculate snowfall rates from the MRR, $Z_{e}-S$ relationships for 35-GHz radars have been used in the past (e.g., Kneifel et al. 2011; Maahn et al. 2014). Recently, a $Z_{e}-S$ relationship for MRR has been developed but only for Antarctica (S17).

We, on the contrary, develop a new relationship particularly suited for a 24-GHz radar. Additionally, we use a new approach to keep the prefactor $a_{\mathrm{zs}}$ variable in time by adding information from concurrent surface observations. We make use of the instantaneous PSD from a disdrometer as Rasmussen et al. (2003) have shown that $a_{\mathrm{zs}}$ depends strongly on the intercept parameter $N_{0}$ of the PSD in the Rayleigh scattering regime. With this approach, the $Z_{e}-S$ relationship takes the local variability of the PSD into account. Thus, the method is less restricted to the location for which it was originally developed. Using this new method compared to a method with a constant $a_{\mathrm{zs}}$, it is expected to improve the resulting snowfall rate. Furthermore, we calculate the snowfall rate also with $Z_{e}$ from a $\mathrm{W}$-band radar to have an independently derived snowfall rate to which the results from the K-band radar can be compared to. The comparison of the resulting snowfall accumulation to an observational in situ reference completes the analysis.

For the derivation of the $Z_{e}-S$ relationship parameters $a_{\mathrm{zs}}$ and $b_{\mathrm{zs}}$, information on microphysical properties of snow particles is required (S17) but not always available or sufficiently well known. These required properties are the terminal fall velocity, PSD, mass, and the backscatter cross section of the ice particles, where the latter is different for each radar frequency. At the high-latitude measurement site in Hyytiälä, Finland, the video-disdrometer Precipitation Imaging Package (PIP) directly measures fall velocity and PSD of snow events from which mass of the snow particles is calculated with hydrodynamic theory (von Lerber et al. 2017). In this study we use snow event measurements from five winters between 2014 and 2018.

In section 2, we give an overview on the measurement sites and data sources. In section 3 , we introduce the basics of the radar-based snowfall-rate retrieval. Section 4 is divided into two parts. First, the $Z_{e}-S$ retrieval development is explained in detail together with an uncertainty analysis based on data from Hyytiälä. Second, because there are no reliable MRR observations available in Hyytiälä during the same time when a cloud radar has been measuring, we test the performance of the new snowfall-rate retrieval methods with measurements from AWIPEV at Ny-Ålesund. At this site, the retrieved parameters are applied to measured $Z_{e}$ values from an MRR and the W-band Microwave Radar for Arctic Clouds (MiRAC-A). The performance of the newly developed relationships is then evaluated for three case studies. A summary of the results and conclusions can be found in section 5 .

\section{Measurement setup}

\section{a. Measurement site Hyytiälä}

The University of Helsinki operates a Forestry Field Station in southern Finland, in Hyytiälä $\left(61.8439^{\circ} \mathrm{N}, 24.2875^{\circ} \mathrm{E} ; 150 \mathrm{~m}\right.$ above mean sea level), $220 \mathrm{~km}$ northwest of Helsinki (Hari and Kulmala 2005). Meteorological instrumentation, including the PIP, is operated in the middle of a clearing since 2014. The PIP is a video disdrometer from the National Aeronautics and Space Administration deployed to Hyytiälä as part of the Global Precipitation Measurement mission (GPM) ground validation program. It is the successor of the Snow Video Imager (SVI) (Newman et al. 2009) with an improved camera and software (Tiira et al. 2016). The principle of this instrument is taking highly resolved images with a video camera that has a frame rate as high as 380 frames per second, which is directed 
toward a 2-m-distant halogen lamp acting as a background illumination (Tiira et al. 2016). The measurement volume is determined by the field of view $(48 \mathrm{~mm} \times 64 \mathrm{~mm})$ and the depth of field (defined by the particles in focus). Particles falling through the volume between light and camera are recorded and a $2 \mathrm{D}$-grayscaled video image is saved. The diskequivalent diameter $D_{\text {deq }}$, that is, the same area of a circular disk as the mapped shadowed area, is then defined from the particle image with a resolution of $0.1 \mathrm{~mm} \times 0.1 \mathrm{~mm}$ (Newman et al. 2009). The diameter $D_{\mathrm{deq}}$ ranges from 0.1 to $26 \mathrm{~mm}$ and is divided into 130 bins, whereas the last bin includes every particle with diameter larger than $26 \mathrm{~mm}$ (von Lerber et al. 2018). The error of the provided particle size from the predecessor of PIP is estimated to be $18 \%$ (error in $D_{\text {deq }}$ ) (Newman et al. 2009).

Due to the observation of consecutive frames at high rate, the fall velocity of a single particle as a function of $D_{\text {deq }}$ (hereafter $D$ ) is recorded. Since the Hyytiälä measurement site is located in a forest-sheltered clearing, the surrounding wind conditions are typically modest or low (mean wind in snowfall cases during 2014-18 is $1.5 \mathrm{~m} \mathrm{~s}^{-1}$ and the vertical wind component was much smaller than the fall velocity) as can be observed with observations from a collocated 3D anemometer. Therefore, it is assumed that the effect of vertical air velocity is small compared to the particle fall velocity, and in the mass retrieval, fall velocity is assumed to be close to the snowflake terminal velocity. This naturally induces uncertainty in the derived masses (Zawadzki et al. 2010). Additionally, as a function of $D$, the PSD is determined for every minute.

\section{b. Measurements at AWIPEV, Ny-Ålesund}

The French-German Arctic research base AWIPEV is located on the Norwegian archipelago Svalbard, in the village of $\mathrm{Ny}$-Ålesund $\left(78.9230^{\circ} \mathrm{N}, 11.9210^{\circ} \mathrm{E} ; 11 \mathrm{~m}\right.$ above mean sea level). The village is situated at the Kongsfjord and close to mountains that are located parallel to the Fjord from northwest to southeast.

Since 2016, the University of Cologne (UoC) is part of the Transregional Collaborative Research Centre (TR 172) on Arctic Amplification: Climate Relevant Atmospheric and Surface Processes, and Feedback Mechanisms (AC) ${ }^{3}$ (Wendisch et al. 2017; Wendisch et al. 2018). Within this project, the UoC operates a cloud radar in Ny-Ålesund with continuous measurements from June 2016 to October 2018 and from June 2019 onward. Since April 2017, continuous measurements from an MRR and the laser disdrometer Particle Size Velocity (PARSIVEL) of UoC are available as well. These instruments are located on the roof of the AWIPEV observatory.

Additionally, used as auxiliary variables in the later case study, measurements from a $10-\mathrm{m}$ tower that include wind and temperature at 2- and 10-m height are available from the Baseline Surface Radiation Network (BSRN) site, operated by AWI (Maturilli 2018). A detailed description about the meteorological sensors installed on the tower and the BSRN site in general can be found in Maturilli et al. (2013).

AWI's humidity and temperature profiler (HATPRO), a microwave radiometer, provides information on vertically integrated liquid water in the atmospheric column, that is, the liquid water path (LWP; Nomokonova et al. 2019a), which is used in this study to detect precipitation and indicate riming. Details on the LWP retrieval can be found in Nomokonova et al. (2019a). The temporal resolution of the LWP is 1-2 s. The LWP accuracy is within $20-25 \mathrm{~g} \mathrm{~m}^{-2}$ (Rose et al. 2005).

\section{1) LASER DISDROMETER: PARSIVEL}

PARSIVEL is an optical laser-disdrometer produced by the manufacturer OTT. A flat laser sheet is transmitted at $650 \mathrm{~nm}$ with an area of $27 \mathrm{~mm} \times 180 \mathrm{~mm}$ and a height of $1 \mathrm{~mm}$ (Battaglia et al. 2010). A voltage decrease occurs when the laser sheet is blocked by particles falling between transmitter and receiver. The fall velocity is measured via the time delay of the particle intercepting the laser beam. Particle size is proportional to the amplitude of the voltage decrease.

Within PARSIVEL's retrieval rationale, measured particles are assumed to be raindrop-like, thus, small particles (diameter smaller than $1 \mathrm{~mm}$ ) are assumed to be spherical. In the middle range $(1-5 \mathrm{~mm})$ particles are assumed to be horizontally oriented oblate spheroids with axial ratio linearly varying from 1 to 0.7 and larger particles (larger than $5 \mathrm{~mm}$ ) have constant axial ratio of 0.7 (Battaglia et al. 2010). The provided output diameter for raindrops can therefore be interpreted as a volume equivalent diameter; however, for irregularly shaped snowflakes, the diameter definition is more arbitrary. Battaglia et al. (2010) have investigated PARSIVEL's ability to measure falling snow in more detail. They found an underestimation of fall velocity for small snow particles and an overestimation for large particles with up to $30 \%-40 \%$ uncertainty. The uncertainty in particle size and fall velocity propagates into the PSD retrieval of the instrument. In this study, we use the measured PSD to fit an exponential function and to retrieve the intercept parameter $N_{0}$. A comparison between the fitted exponential PSD from PIP and a PARSIVEL measuring in Hyytiälä (not shown) revealed a small difference (mean difference in respect to the range of values is $1.7 \%$ ) in $N_{0}$, from which we concluded that the retrieved $N_{0}$ with PARSIVEL can be applied to the later defined $Z_{e}-S$ relation for MRR in section 4 .

\section{2) MICRO RAIN RADAR}

The MRR is a vertically pointing frequency modulated continuous wave (FM-CW) Doppler radar manufactured by METEK GmbH (Klugmann et al. 1996). It operates at a frequency of $f=24 \mathrm{GHz}$ (K band; wavelength $\lambda=12.38 \mathrm{~mm}$ ). Relative to (pulsed) radars in the same frequency range, the MRR has a low power consumption of $25 \mathrm{~W}$. If the installed dish heater is turned on, a consumption of $500 \mathrm{~W}$ is added. The heating system prevents snow accumulation on the parabolic offset dish antenna, which has an effective aperture diameter of $0.5 \mathrm{~m}$. The beamwidth of the signal is $1.5^{\circ}$. All output variables are internally averaged over 10 -s time steps to generate a 1-min data resolution.

The MRR was originally built to measure liquid precipitation and was not well suited for solid precipitation. Maahn and Kollias (2012) developed an Improved MRR Processing Tool (IMProToo) for better snow observations through dealiasing the Doppler spectra and removing noisy signals. The lowest detectable value thus decreased from $-5 \mathrm{~dB} Z$ for Metek's standard analyzing method to $-14 \mathrm{~dB} Z$ for the new proposed 
method by Maahn and Kollias (2012). At Ny-Ålesund, the first MRR bin is at a height of $30 \mathrm{~m}$. The vertical resolution of the radar bins is set to $30 \mathrm{~m}$ resulting in a maximum height range of $930 \mathrm{~m}$. We are interested in snowfall at the ground, but the lowest radar bins usually suffer from noisy signals. Additionally, the snowfall rate calculated from MRR is compared to the snowfall rate from the $\mathrm{W}$-band radar, whose lowest radar bin is at a height of about $100 \mathrm{~m}$ (see next section). For the MRR, we thus calculated a vertically averaged $Z_{e}$ from the three range bins between 120 and $180 \mathrm{~m}$ for each time step.

\section{3) MicRowAVE RADAR/RADIOMETER FOR ARCTIC CLOUDS}

The active component of MiRAC is a W-band radar (MiRAC-A), operating at $f=94 \mathrm{GHz}(\lambda=3.19 \mathrm{~mm})$ and manufactured by Radiometer Physics GmbH. The separation into one transmitting and one receiving antenna (beamwidth of $0.48^{\circ}$ ) allows the continuous wave transmission and the receiving antenna is protected from saturation (Küchler et al. 2017). MiRAC-A has a very low transmitter power consumption of $1.5 \mathrm{~W}$ but a strong blower that ensures a precipitationfree antenna surface. The uncertainty of $Z_{e}$ is on the order of $0.5 \mathrm{dBZ}$, and the lowest detectable signal is in the range of -65 to $-50 \mathrm{~dB} Z$ at the distance of $100-600 \mathrm{~m}$ depending on chirp settings and atmospheric state (Mech et al. 2019). The available height range starts at about $100 \mathrm{~m}$ and can reach up to $12 \mathrm{~km}$ with a vertical resolution of maximum $3.2 \mathrm{~m}$. Similar to MRR, we averaged the cloud radar $Z_{e}$ over the height range between 120 and $180 \mathrm{~m}$ above ground. The internal time sampling is at a rate of $2.4 \mathrm{~s}$; however, to have a better comparison to the MRR measurements, we average the values over $1 \mathrm{~min}$.

\section{4) Precipitation gauge: Pluvio}

The Pluvio2 L 400 (herein, Pluvio) is an automated weighing gauge with an orifice of $400 \mathrm{~cm}^{2}$ and is manufactured by OTT. The gauge is suitable for observing both liquid and solid precipitation. The latter is always given as the amount equivalent to liquid water and the phase distinction need to be obtained via temperature measurements. In this study, we use the nonreal time accumulated precipitation in $\mathrm{mm} \mathrm{h}^{-1}$ that has an absolute (relative) accuracy of $\pm 0.1 \mathrm{~mm}( \pm 1 \%)$ (OTT 2016). In general, gauges are very prone to the underestimation of solid precipitation due to high wind, or overestimation due to blowing snow. Therefore, different wind shieldings have been designed, used, and tested in the last decades to limit the uncertainty of gauge measurements (Rasmussen et al. 2012). The Pluvio in Ny-Ålesund is surrounded by a single Alter wind shield. Rasmussen et al. (2014) compared a single Alter wind shield to a Double-Fence Intercomparison Reference gauge in dry snowfall and found that the undercatchment of snow is approximately less than $30 \%$ with the single Alter wind shield at a wind speed smaller than $5 \mathrm{~m} \mathrm{~s}^{-1}$ increasing to $60 \%$ with higher wind speeds of $9 \mathrm{~m} \mathrm{~s}^{-1}$ or more.

\section{Radar-based snowfall-rate retrieval}

Because of the complex microphysics of snow, the correct estimation of snowfall from radar measurements remains especially challenging as the parameter values for the $Z_{e}-S$ relationship are numerous and typically event specific.

\section{a. Snowfall rate}

The snowfall rate in the liquid equivalent units of millimeters per hour can be calculated from the density of liquid water $\rho_{w}$, the mass-size relationship $m(D)$, the fall velocity-size relationship $v(D)$, all in SI units, and the PSD $N(D)\left(\mathrm{mm}^{-1} \mathrm{~m}^{-3}\right)$ :

$$
S=\frac{3600}{\rho_{w}} \int_{D_{\min }}^{D_{\max }} m(D) v(D) N(D) d D .
$$

The $D_{\min }$ and $D_{\max }$ are the minimum and maximum observed particle size of PIP $\left(D_{\mathrm{deq}}\right)$, respectively, with both in units of millimeters.

For this study, a dataset consisting of the variables $v(D, t)$, $N(D, t)$, and $m(D, t)$ were used. These variables have been derived from the PIP measurements with which we calculated a time-dependent snowfall rate, because all measurements are averaged over a 5-min time interval where temperatures were below $0{ }^{\circ} \mathrm{C}$. In total, 4947 of these time intervals are available from five winters between 31 January 2014 and 2 April 2018. The first two years of this dataset (Moisseev 2020) are described in Tiira et al. (2016) and von Lerber et al. (2017) and utilized in, for example, Moisseev et al. (2017), Falconi et al. (2018), Li et al. (2018), Mason et al. (2018), Leinonen et al. (2018), Mason et al. (2019), Tyynelä and von Lerber (2019), and Chase et al. (2020). The dataset used in this study uses measurements of additional three years but is based on the cited dataset.

The fall velocity of snow particles and PSD are a direct output of PIP. To account for a continuous size distribution, the measured 5-min mean PSD is approximated with the exponential function: $N(D)=N_{0} \exp (-\Lambda D)$. To derive the exponential PSD, the intercept parameter $N_{0}(t)$ and the slope $\Lambda(t)$ are calculated with the method of moments (e.g., Moisseev and Chandrasekar 2007; Ulbrich and Atlas 1998) from the PSD measured by PIP. The applied mass retrieval is from von Lerber et al. (2017), where the parameterization of Mitchell and Heymsfield (2005) for the hydrodynamic theory has been utilized and showed to describe the climatological snow conditions in Finland well. In hydrodynamic theory, the gravity and atmospheric drag influencing the falling particle are set equal, and therefore the mass of a snowflake can be estimated from observations of fall velocity, particle dimensions, and area characteristics.

\section{b. Reflectivity}

The equivalent radar reflectivity factor can be computed as

$$
Z_{e}=\frac{\lambda^{4}}{\pi^{5}|K|^{2}} \int_{D_{\min }}^{D_{\max }} \sigma_{b}(D) N(D) d D
$$

where $Z_{e}$ is given in linear units. The wavelength $\lambda$ is in millimeters; the dielectric factor $|K|^{2}$ is unitless; the backscatter cross section $\sigma_{b}(D)$ is in millimeters squared, and $D_{\min }, D_{\max }$, and $N(D)$ have the same units as in Eq. (1). In this study, we calculate $Z_{e}$ for two different wavelengths as well as for 5-min time intervals. Thus, we use the time-dependent exponential 
$N(D, t)$ in Eq. (2), which has been fitted to the observations as described in the previous section. For the dielectric factor, which depends on wavelength and temperature, we used $|K|^{2}=$ 0.92 for $\mathrm{K}$ band and $\sim 0.76$ for $\mathrm{W}$ band. Also, wavelengthdependent $\sigma_{b}(D)$ values were computed using different approaches that are explained in the following.

For the MRR frequency ( $\mathrm{K}$ band), that is, $24 \mathrm{GHz}$, the softspheroid particle model in combination with effective medium approximation (Sihvola 1999) and T-matrix method (TMM) can be applied (Tyynelä et al. 2011; Falconi et al. 2018). Although it is shown (e.g., in Schrom and Kumjian 2018) that for single crystals the dual-polarization scattering properties cannot be adequately computed with soft-spheroid approximation, here, we apply the approximation for snow particle mixtures, and on average, the forward simulated $Z_{e}$ is reasonably well described compared to observations at $\mathrm{K}$ band (Falconi et al. 2018). At higher frequencies, for example, W band, this particle model starts to fail (Leinonen et al. 2012; Kneifel et al. 2015). To compute the K-band $Z_{e}$, the softspheroid particle model with an aspect ratio of 0.6 , which works both for rimed and unrimed snowflakes (Li et al. 2018), was used. Given the particle mass, maximum dimension, and aspect ratio, the snowflake refractive index is computed using the Bruggeman approximation (Bruggeman 1935). The backscattering cross section of snowflakes are then computed using TMM (Mishchenko and Travis 1994; Leinonen 2014, 2018).

To calculate $\sigma_{b}$ for the $\mathrm{W}$ band, the single-particle scattering databases of Leinonen and Moisseev (2015), Leinonen and Szyrmer (2015), and Tyynelä and von Lerber (2019) were used. All databases are different and represent particles with different properties. The snowflakes were modeled mimicking physical processes responsible for ice particle formation, vapor deposition, aggregation (Leinonen and Moisseev 2015), and, additionally, riming (Leinonen and Szyrmer 2015), or as fractal particles (Tyynelä and von Lerber 2019). The scattering properties of these complex particles are computed using the discrete dipole approximation (DDA) (Yurkin and Hoekstra 2011). To determine a backscattering cross section for a given snowflake we have used linear interpolation in the $\log -\log$ space, where $\sigma_{b}(D)$ is a function of the maximum dimension and particle mass. For this, all the databases were combined into one.

\section{Results}

\section{a. Snowfall-rate retrieval development}

For the development of the snowfall-rate retrieval, we solved the $Z_{e}-S$ relationship for $S$. and used the following equation for further calculations:

$$
S=\left(\frac{1}{a_{\mathrm{zs}}} Z_{e}\right)^{1 / b_{\mathrm{zs}}} .
$$

Two methods are developed to retrieve $a_{\mathrm{zs}}$ and $b_{\mathrm{zs}}$ and are presented in the following subsections. An overview scheme of all variables (measured, derived, and simulated) and how they are used to calculate $Z_{e}$ and $S$ is shown in Fig. 1 .

\section{1) AVERAge $Z_{E}-S$ RELATIONShiP}

For the so-called average $Z_{e}-S$ relationship the calculated reflectivity [Eq. (2)] is plotted against the calculated snowfall rate [Eq. (1)] on logarithmic scales for all available 4947 fiveminute time steps for both the K-band and the W-band radars. From the resulting scatterplot (Fig. 2) the exponent and prefactor can be derived with a total least squares fit (TLS or orthogonal distance regression) (Boggs and Rogers 1990; Boggs et al. 1992), which accounts for the uncertainty in both $S$ and $Z_{e}$. For $\mathrm{K}$ band, the parameters $a_{\mathrm{zs}}=77.61$ and $b_{\mathrm{zs}}=1.22$ are obtained. For W band, we get $a_{\mathrm{zs}}=18.18$ and $b_{\mathrm{zs}}=0.98$. By constraining the exponent value $b_{\mathrm{zs}}$ to be constant, the 0.05 and 0.95 quantile for the prefactor can be derived from the TLS fit. The value range of $30.15 \leq a_{\mathrm{zs}} \leq 205.83$ for $\mathrm{K}$ band shows the wide variation of the prefactor values. For $\mathrm{W}$ band, the value range is lower with $11.22 \leq a_{\mathrm{zs}} \leq 28.36$. Especially in the K-band frequency, for one specific $Z_{e}$ value, a variety of different $S$ values in the order of a magnitude can be retrieved (e.g., for $Z_{e}=10^{-1} \mathrm{~mm}^{6} \mathrm{~m}^{-3}$ the range in $S$ is from 10 to $\left.10^{-2} \mathrm{~mm} \mathrm{~h}^{-1}\right)$. By definition, the prefactor variation in $\mathrm{W}$ band is smaller because of a smaller $Z_{e}$ range with a maximum $Z_{e}$ of $10^{2} \mathrm{~mm}^{6} \mathrm{~m}^{-3}$ as compared with $10^{3} \mathrm{~mm}^{6} \mathrm{~m}^{-3}$ for $\mathrm{K}$ band (see Fig. 2). For further reference, this method is called AVE_K and AVE_W for the average relationship for $\mathrm{K}$ and $\mathrm{W}$ band, respectively.

\section{2) ANALytical $Z_{E}-S$ RELATIONSHIP}

Following von Lerber et al. (2017), our so-called analytical $Z_{e}-S$ relationship considers the time-dependency of all parameters and provides an instantaneous $Z_{e}-S$ relationship for each time step. For better readability, the time dependency of each variable is omitted in the following equations.

When assuming power laws for the mass- and fall velocitydimensional relationships, the exponential PSD function, and by integrating over an infinite diameter size on which the complete Gamma function can be applied, Eq. (1) can be rewritten into more detailed components:

$$
\begin{aligned}
S & =\frac{1}{\rho_{w}} \int_{0}^{\infty} a_{m} D^{b_{m}} a_{v} D^{b_{v}} N_{0} \exp (-\Lambda D) d D \\
& =\frac{1}{\rho_{w}} a_{m} a_{v} N_{0} \Lambda^{-\left(b_{m}+b_{v}+1\right)} \Gamma\left(b_{m}+b_{v}+1\right) \\
& =N_{0} F_{S} \Gamma\left(b_{m}+b_{v}+1\right),
\end{aligned}
$$

where $F_{S}$ comprises the remaining variables.

Doing the same for the reflectivity, Eq. (2) can be written as

$$
\begin{aligned}
Z_{e} & =\frac{\lambda^{4}}{\pi^{5}|K|^{2}} \int_{0}^{\infty} a_{\sigma} D^{b_{\sigma}} N_{0} \exp (-\Lambda D) d D \\
& =\frac{\lambda^{4}}{\pi^{5}|K|^{2}} a_{\sigma} N_{0} \Lambda^{-\left(b_{\sigma}+1\right)} \Gamma\left(b_{\sigma}+1\right) \\
& =N_{0} F_{Z_{e}} \Gamma\left(b_{\sigma}+1\right) .
\end{aligned}
$$

By inserting Eqs. (4) and (5) into the $Z_{e}-S$ relationship, the analytical solution for the two parameters in dependency of time is obtained 


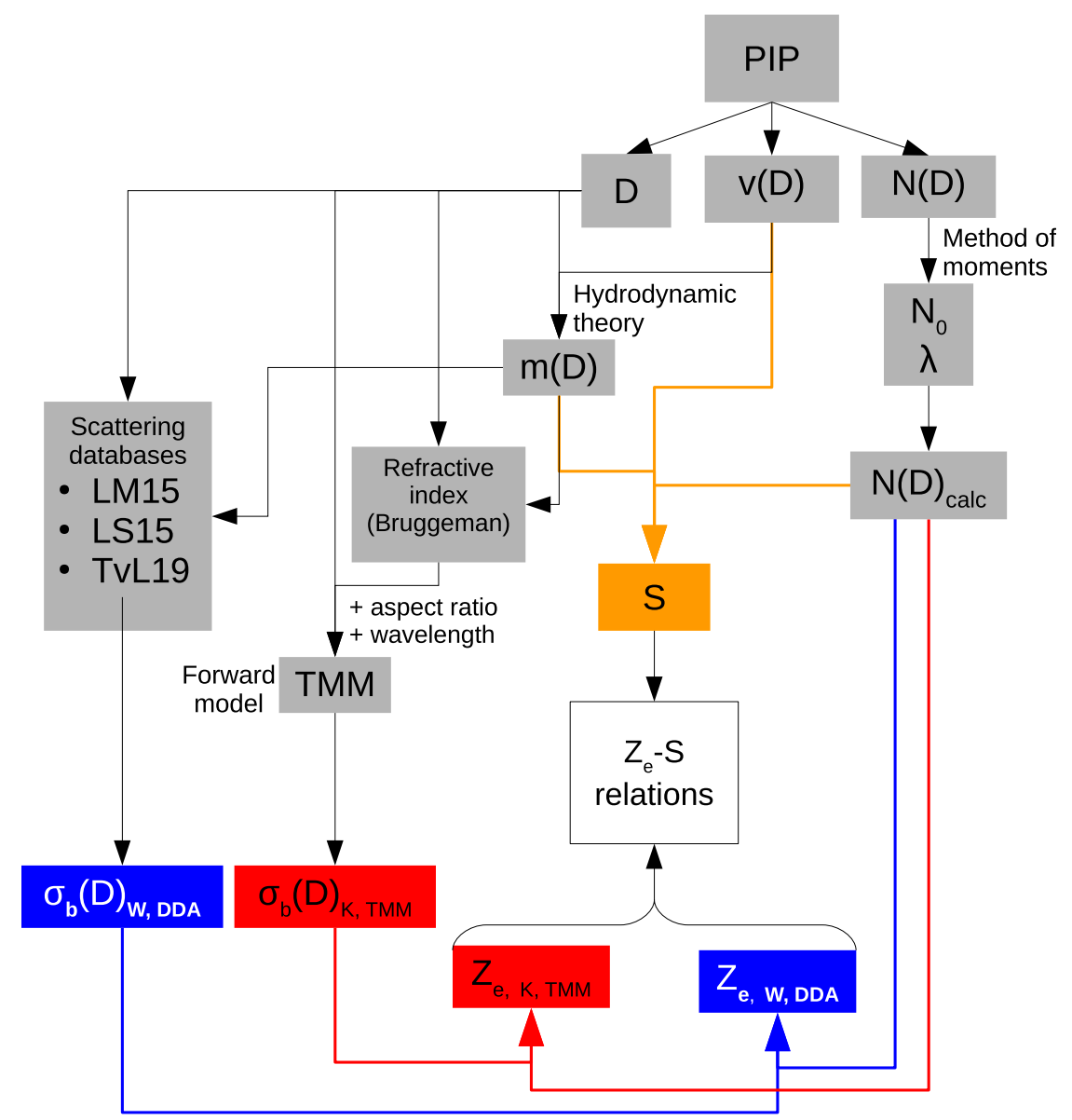

FIG. 1. Overview scheme of measured, calculated, and simulated variables needed to retrieve the parameters of the $Z_{e}-S$ relationship. For the scattering databases utilizing the DDA method, the following abbreviations are used: Leinonen and Moisseev (2015) (label LM15), Leinonen and Szyrmer (2015) (label LS15), and Tyynelä and von Lerber (2019) (label TvL19). All input variables for the retrieval development are displayed in gray. The snowfall rate retrieved from the in situ data is highlighted in yellow. The colors red and blue are related to K-band and W-band radar, respectively, and are also used in the following figures to distinguish between the results from the two radars.

$$
Z_{e}=\underbrace{N_{0} F_{Z_{e}}\left(N_{0} F_{S}\right)\left[-\left(\frac{b_{\sigma}+1}{b_{m}+b_{v}+1}\right)\right]}_{=a_{\mathrm{zS}}} \underbrace{S\left(\frac{b_{\sigma}+1}{b_{m}+b_{v}+1}\right)}_{S^{b_{\mathrm{zS}}}}
$$

The prefactor $a_{\mathrm{zs}}$ is very complex and is dependent on all components of both $Z_{e}$ and $S$. However, von Lerber et al. (2017), in accordance with Rasmussen et al. (2003), have found $a_{\mathrm{zs}}$ to be strongest dependent on the PSD intercept parameter $N_{0}$ in the Rayleigh scattering regime. In contrast, the exponent $b_{\mathrm{zs}}$ simply reduces to

$$
b_{\mathrm{zs}}=\frac{b_{\sigma}+1}{b_{m}+b_{v}+1},
$$

For the calculation of $b_{\mathrm{zs}}$, the parameters $b_{m}$ and $b_{\sigma}$ are calculated from polynomial fits (in log space) with which the power laws for $m(D, t)$ and $\sigma(D, t)$ are determined. For $b_{v}$, the mean value of 0.2 is used (Tiira et al. 2016). Because the exponent $b_{\mathrm{zs}}$ is a function of time, a mean over all time steps is calculated to get a fixed parameter for K band: $b_{\mathrm{zs}}=1.47$. For $\mathrm{W}$ band we get $b_{\mathrm{zs}}=1.14$. The dependency of $a_{\mathrm{zs}}$ on the intercept parameter $N_{0}$ is investigated in more detail. Equation (6) is solved for $a_{\mathrm{zs}}$ for each time step with the aforementioned fixed mean value of $b_{\mathrm{zs}}$ and plotted against $\log _{10}\left(N_{0}\right)$ (see Fig. 3). Especially for $\mathrm{K}$ band, the value range of $a_{\mathrm{zs}}\left(N_{0}\right)$ is on the order of $10^{2}-10^{3}$. The large scatter of $a_{\mathrm{zs}}$ at lower $N_{0}$ values reduces toward larger $N_{0}$ values. The prefactor for the W-band relationship does not show a strong dependency toward $N_{0}$ : values range from about 10 to 100 . A linear least squares fit is used to approximate a power law for $a_{\mathrm{zs}}\left[N_{0}(t)\right]$ further called $a_{N_{0}, \text { fit }}$. This method is further called ANA_K and ANA_W for the analytical relation for $\mathrm{K}$ and $\mathrm{W}$ band, respectively.

\section{3) UNCERTAINTY ANALYSIS}

An uncertainty analysis has been performed to determine the impact of the natural variability in snowfall properties 


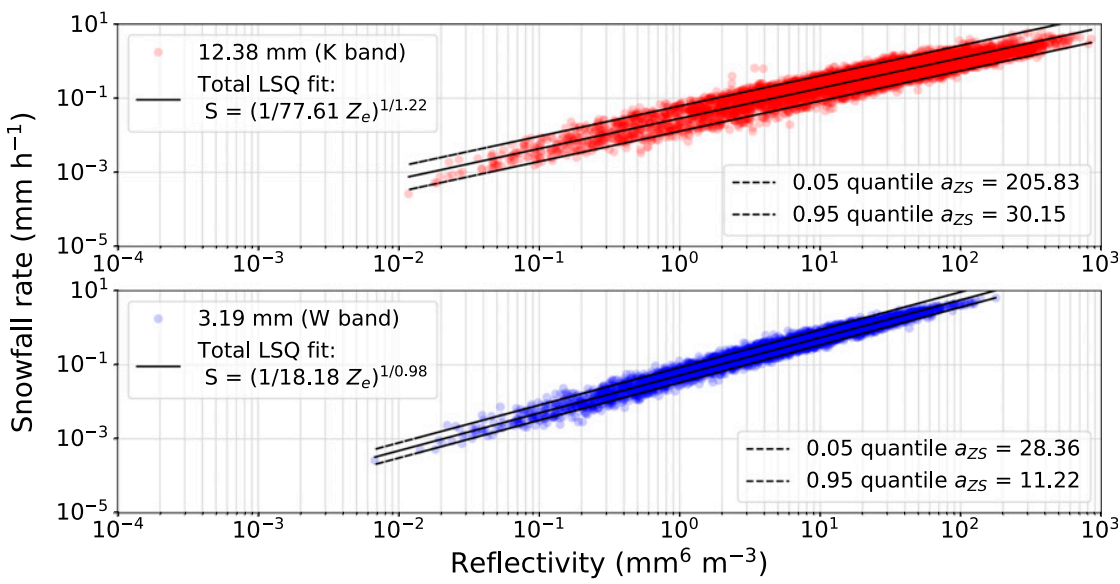

FIG. 2. Scatterplot of calculated snowfall rate $\left(\mathrm{mm} \mathrm{h}^{-1}\right)$ vs radar reflectivity $\left(\mathrm{mm}^{6} \mathrm{~m}^{-3}\right)$ from PIP measurements and radar cross-sectional simulations for (top) K-band and (bottom) $\mathrm{W}$-band radars. The TLS fit is indicated by the solid black line. The dashed black lines use the same exponent of the TLS fit but represent the 0.05 and 0.95 quantile of all available points for the value range between the minimum and maximum prefactor of $a_{\mathrm{zs}}$.

[PSD, $m(D)$, and $v(D)]$ on the retrieved snowfall rate. This variability is accounted for by using the observations recorded over five winters in Finland from 2014 to 2018, which cover different types of snowfall (Tiira et al. 2016; Moisseev et al. 2017). We compute the root-mean-square error (RMSE) of the snowfall rate $\left(S_{\mathrm{RMSE}}\right)$ for each retrieval method as follows: For all observations of PSD, $m(D)$ and $v(D)$, as a function of time, a reflectivity and snowfall rate pair is computed as described in section 3. We use this snowfall rate as the true measured snowfall rate. The estimated snowfall rate is computed with AVE_K, AVE_W, and ANA_K, ANA_W, respectively. Note that the estimated uncertainty represents the uncertainty of the regression and does not include measurement uncertainties.

Since the observations showed that the prefactor $a_{\mathrm{zs}}$ depends on $N_{0}$, the RMSE is displayed for both $Z_{\mathrm{e}}-S$ methods and frequencies as a function of $\log _{10}\left[N_{0}(t) /\left(\mathrm{mm}^{-1} \mathrm{~m}^{-3}\right)\right]$ in Fig. 4. We choose the display range between 2 and $5 \log _{10}\left[N_{0}(t) /\left(\mathrm{mm}^{-1} \mathrm{~m}^{-3}\right)\right]$ with an interval step of 0.25 . The lower and upper limit originate from the minimum and maximum available total amount of the particles within the PSD.

Within this $\log _{10}\left[N_{0}(t)\right]$ range, the calculated $S_{\mathrm{RMSE}}$ for AVE_K varies from a minimum of 0.11 up to a maximum of $0.96 \mathrm{~mm} \mathrm{~h}^{-1}$, whereas $S_{\mathrm{RMSE}}$ for ANA_K stays below $0.18 \mathrm{~mm} \mathrm{~h}^{-1}$ along the whole range. From the large spread of $a_{\mathrm{zs}}$ values for $\mathrm{K}$ band in Fig. 3, we expect a higher RMSE for AVE_K in general, and especially for the higher $\log _{10}\left[N_{0}(t)\right]$ values because of the low quantity of data points. The RMSE in snowfall rate for AVE_W and ANA_W has a maximum at 0.31 and $0.26 \mathrm{~mm} \mathrm{~h}^{-1}$, respectively. These lower values are expected as well, because of the order-of-magnitude-smaller

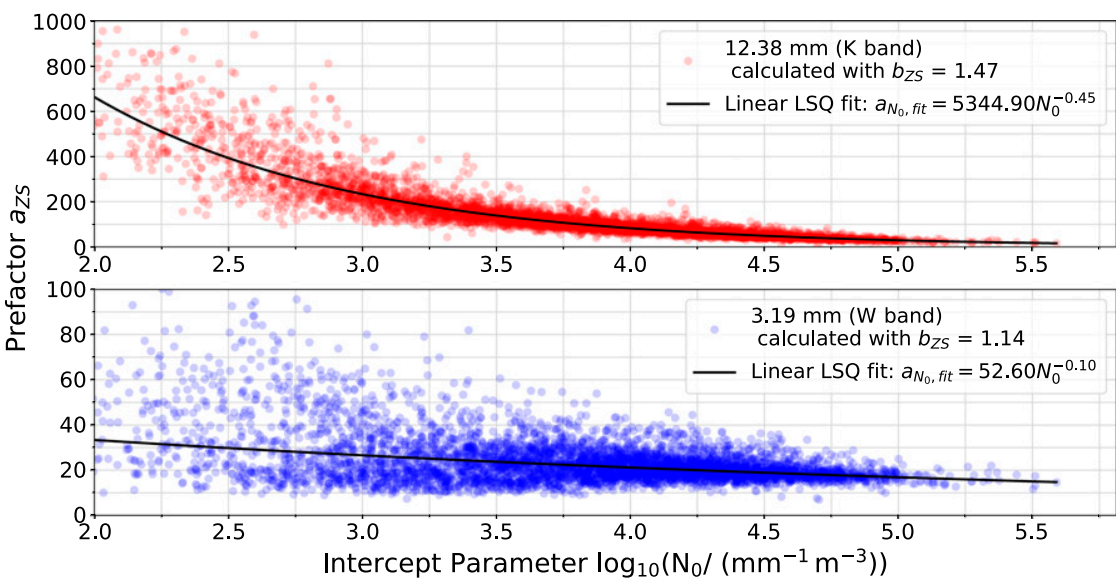

FIG. 3. Prefactor $a_{\mathrm{zs}}\left(\mathrm{mm}^{6-b_{\mathrm{zs}}} \mathrm{h}^{b_{\mathrm{zs}}} \mathrm{m}^{-3}\right)$ in dependency of the logarithm of the intercept parameter $N_{0}\left\{\log _{10}\left[N_{0} /\left(\mathrm{mm}^{-1} \mathrm{~m}^{-3}\right)\right]\right\} ; a_{\mathrm{zs}}$ has been calculated by solving Eq. (3) for $a_{\mathrm{zs}}$ using the mean value of $b_{\mathrm{zs}}$ from Eq. (7). Results are shown for (top) K-band (red) and (bottom) $\mathrm{W}$-band (blue) radars. Note the reduced $y$-axis range by one order of magnitude in the bottom panel. The solid black line in each panel shows the linear least squares fit. 


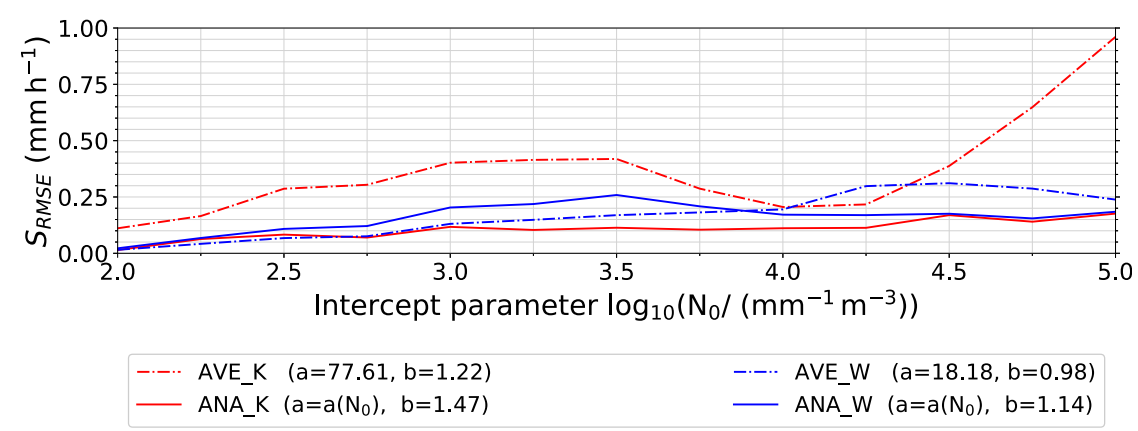

FIG. 4. Uncertainty (RMSE) of the calculated snowfall rate as a function of the intercept parameter $N_{0}$ of the particle size distribution. The uncertainty is provided for the average (dash-dotted) and the analytical $Z_{e}-S$ relationship (solid) for K-band (red) and W-band (blue) radars, respectively.

spread in $a_{\mathrm{zs}}$ values for $\mathrm{W}$ band relative to $\mathrm{K}$ band in Fig. 3. One main result of this uncertainty analysis is therefore that for $\mathrm{K}$ band, $S_{\mathrm{RMSE}}$ can be strongly reduced when using $a_{\mathrm{zs}}$ as a function of $N_{0}$ (ANA_K), which cannot be seen for W band.

To be able to provide a general uncertainty of our derived methods, we can directly assign the mean over the considered $\log _{10}\left[N_{0}(t)\right]$ for the average $Z_{e}-S$ relationships as both parameters are constants. For ANA_K and ANA_W, however, the prefactor $a\left(N_{0}\right)$ is different for each $N_{0}$, which, on the other hand, impacts the snowfall-rate uncertainty. Thus, we provide a first order polynomial regression for the RMSE of $S$ :

$$
S_{\mathrm{RMSE}}\left[\log _{10}\left(N_{0}\right)\right]=p_{1} \log _{10}\left(N_{0}\right)+p_{2} .
$$

The computed parameters $p_{1}$ and $p_{2}$ can be found in Table 1 . In addition, we computed a mean value of $S_{\text {RMSE }}$ for ANA_K and ANA_W to directly compare it with the corresponding mean value of AVE_K and AVE_W. While for AVE_K the mean value of the $S_{\mathrm{RMSE}}$ is around $0.37 \mathrm{~mm}$, the mean $S_{\mathrm{RMSE}}$ for ANA_K is only $0.11 \mathrm{~mm} \mathrm{~h}^{-1}$. Individual $S_{\text {RMSE }}$ values for ANA_K range from 0.05 to $0.17 \mathrm{~mm} \mathrm{~h}^{-1}$ [Eq. (8)] within the displayed $\log _{10}\left[N_{0}(t)\right]$ range. The $S_{\text {RMSE }}$ mean value for $\mathrm{W}$-band reflectivities only slightly improves when $a\left(N_{0}\right)$ is used instead of the constant $a_{\mathrm{zs}}$. The mean RMSE for ANA_W results in an uncertainty of $0.16 \mathrm{~mm} \mathrm{~h}^{-1}$ and for AVE_W in $0.17 \mathrm{~mm} \mathrm{~h}^{-1}$. This marginal improvement does not justify the higher computational effort of ANA_W. Thus, in the following application of the new $Z_{e}-S$ relationships, we further use ANA_K and AVE_W. A summary of all developed $Z_{e}-S$ relationship parameters as well as their uncertainty values and functions can be found in Table 1 .

\section{b. Application of snowfall-rate retrieval parameters}

In this section we apply the developed snowfall-rate retrievals from Hyytiälä data to measured reflectivities of the MiRAC-A and MRR operated at AWIPEV. Especially there, it is important to have ground-based radar retrieved snowfall rates considering the scarce ground-based observation network of in situ point-measurements only, as well as the harsh orographic and weather conditions in the Arctic. As a consequence, Ny-Ålesund could additionally provide improved ground validation for satellite-based snowfall retrievals at high latitudes. At AWIPEV, detailed in situ snowfall particle observations for a retrieval development in Ny-Ålesund are not available. If $Z_{e}-S$ relationships from the literature are used to retrieve snowfall at AWIPEV, we need to rely on the assumption that the snow particles at this site match the ones for which the relationships were originally developed. With our own relationships we like to emphasize that we do not need to know the microphysical properties of snow but account for the variability in snow formation by including the PSD intercept parameter. Note, that, because of missing MRR and cloud radar $Z_{e}$ measurements for a same time frame in Hyytiälä, we could not directly test the relations at this site.

We will demonstrate by means of three case studies that our new relationships developed from Hyytiälä data work well at a location, $18^{\circ}$ farther north, in the Arctic. First, we evaluate in detail the retrieved snowfall rate on 7 February 2018 and also

TABLE 1. Overview table of calculated parameters $a_{\mathrm{zs}}$ and $b_{\mathrm{zs}}$ from two different methods deriving the $Z_{e}-S$ relationship and the uncertainty in $S$ for two radar wavelengths. The boldface entries highlight the best parameters used for further evaluation with measured $Z_{e}$ values.

\begin{tabular}{|c|c|c|c|c|}
\hline & $a_{\mathrm{zs}}\left(\mathrm{mm}^{6-b_{\mathrm{zs}}} \mathrm{h}^{b_{\mathrm{zs}}} \mathrm{m}^{-3}\right)$ & $b_{\mathrm{zs}}$ & $S_{\text {RMSE }}$ mean $\left(\mathrm{mm} \mathrm{h}^{-1}\right)$ & $S_{\text {RMSE }}\left[\log _{10}\left(N_{0}\right)\right]\left(\mathrm{mm} \mathrm{h}^{-1}\right)$ \\
\hline AVE_K & 77.61 & 1.22 & 0.37 & - \\
\hline ANA_K & $\mathrm{a}\left(\mathrm{N}_{0}\right)=5344.9 \mathrm{~N}_{0}^{-0.45}$ & 1.47 & 0.11 & $\begin{array}{l}\quad=\mathbf{0 . 0 4} \log _{\mathbf{1 0}}\left(\boldsymbol{N}_{\mathbf{0}}\right)-\mathbf{0 . 0 3} \\
\text { (values range from } 0.05 \text { to } 0.17 \text { ) }\end{array}$ \\
\hline AVE_W & 18.18 & 0.98 & 0.17 & - \\
\hline ANA_W & $a\left(N_{0}\right)=52.6 N_{0}^{-0.1}$ & 1.14 & 0.16 & $\begin{array}{l}\quad=0.04 \log _{10}\left(N_{0}\right)-0.02 \\
\text { (values range from } 0.1 \text { to } 0.22 \text { ) }\end{array}$ \\
\hline
\end{tabular}




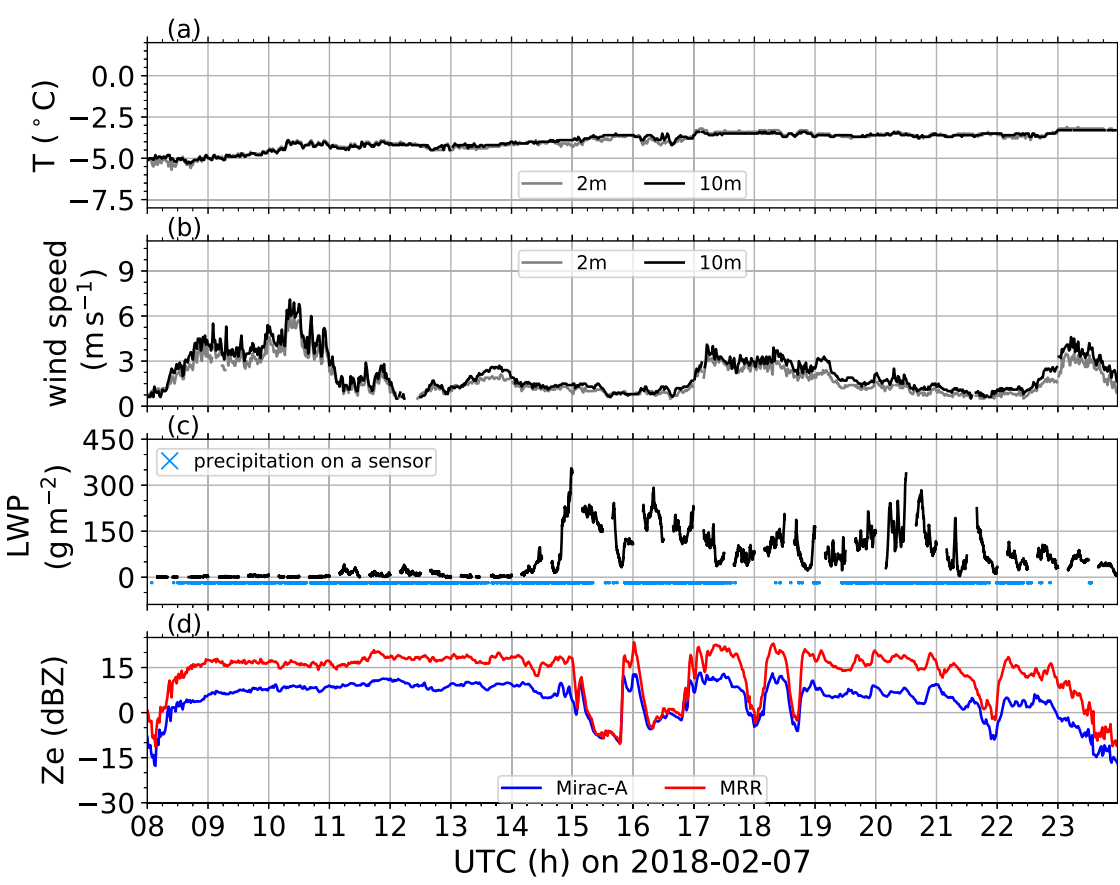

FIG. 5. Time series of (a) temperature $\left({ }^{\circ} \mathrm{C}\right)$, (b) wind speed $\left(\mathrm{m} \mathrm{s}^{-1}\right)$ at 2- (gray) and $10-\mathrm{m}$ (black) height, (c) LWP $\left(\mathrm{g} \mathrm{m}^{-2}\right)$ with a precipitation flag indicating possible water on the microwave radiometer radome, and (d) vertically averaged $(120-180 \mathrm{~m})$ radar reflectivity $(\mathrm{dBZ})$ of the W-band radar MiRAC-A (blue) and the K-band radar MRR (red) at Ny-Ålesund at 0800-2359 UTC 7 Feb 2018.

compare our results to results of other $Z_{e}-S$ relationships from the literature. As observational reference, we use the snowfall rate and accumulated snowfall from Pluvio. For the latter, low wind speeds are of great importance due to otherwise possible undercatchment. Thus, to be sure that we are looking at pure snowfall events and to reduce wind effects in the Pluvio measurements, we restricted the analysis to times with temperatures well below $0^{\circ} \mathrm{C}$ at the surface and wind speeds mostly below $5 \mathrm{~m} \mathrm{~s}^{-1}$ (Figs. 5a,b). The snowfall event on 7 February 2018 satisfies these conditions.

The time series of LWP provides more insight into the snowfall event (Fig. 5c). During the case study, the LWP varies between 0 and $300 \mathrm{~g} \mathrm{~m}^{-2}$, where increased values (higher than
$150 \mathrm{~g} \mathrm{~m}^{-2}$ ) indicate riming. The $Z_{e}$ values of both radars (Fig. 5d) reveal a similar temporal development and differ from each other in the expected range when operating at the used frequencies.

In addition to our two derived relationships, we applied nine different $Z_{e}-S$ relationships from the literature, five for the MRR and four for the MiRAC-A reflectivities (Table 2). Four of the five MRR relationships, three from Kulie and Bennartz (2009, hereinafter KB09) and one from Matrosov (2007, hereinafter M07), were originally derived for a $35-\mathrm{GHz}$ radar. However, Maahn et al. (2014) concluded that the backscattering difference between 35 and $24 \mathrm{GHz}$ is less than $0.5 \mathrm{~dB}$ and directly used the parameters of the $Z_{e}-S$ relationship for

TABLE 2. The $Z_{e}-S$ relationships of this study (ANA_K; AVE_W) and from literature used for two radar systems, i.e., MRR (K band) and MiRAC-A (W band), as well as the corresponding accumulated snowfall (mm) at Ny-Ålesund on 7 Feb 2018. The abbreviated forms in KB09 are the representative ice models used for the snowfall-rate retrieval: ag = aggregates; $b r=$ three-bullet rosettes, and sp $=$ lowdensity spherical snow particles.

\begin{tabular}{|c|c|c|c|c|c|}
\hline & Total $(\mathrm{mm})$ & $Z_{e}(\mathrm{MRR})$ & Total $(\mathrm{mm})$ & $Z_{e}(\mathrm{MiRAC}-\mathrm{A})$ & Total $(\mathrm{mm})$ \\
\hline Pluvio & 5.91 & & & & \\
\hline ANA_K & & $a\left(N_{0}\right) S^{1.47}$ & 4.72 & & \\
\hline AVE_W & & & & $18.18 S^{0.98}$ & 4.39 \\
\hline KB09ag & & $313.29 S^{1.85}$ & 4.78 & $56.43 S^{1.52}$ & 3.00 \\
\hline KB09br & & $24.04 S^{1.51}$ & 20.94 & $13.16 S^{1.40}$ & 7.49 \\
\hline KB09sp & & $19.66 S^{1.74}$ & 22.02 & $2.19 S^{120}$ & 30.66 \\
\hline M07 & & $56.00 S^{1.20}$ & 11.91 & $10.00 S^{0.80}$ & 7.56 \\
\hline S17 & & $18.00 S^{1.10}$ & 33.51 & - & - \\
\hline
\end{tabular}




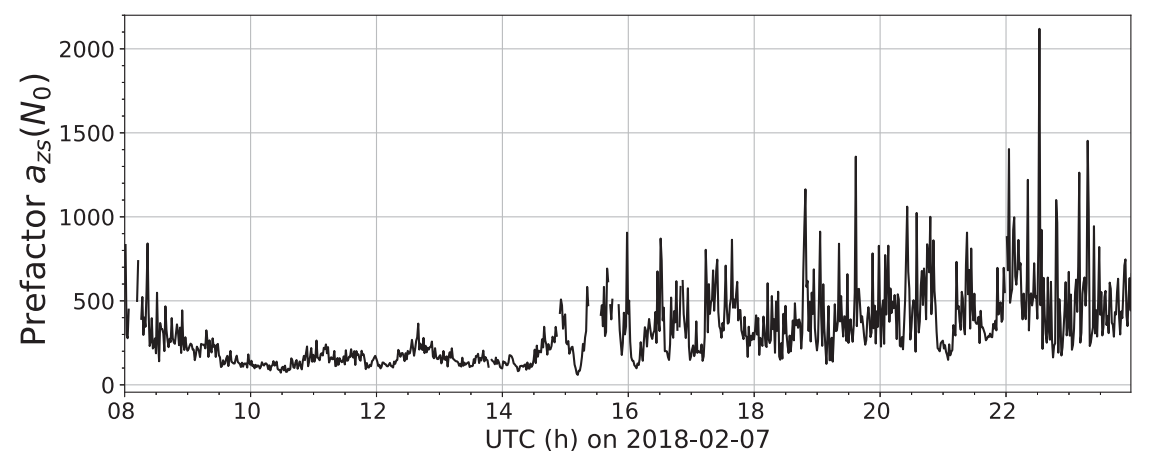

FIG. 6. Time series of the instantaneous prefactor $a_{\mathrm{zs}}\left(\mathrm{mm}^{6-b_{\mathrm{zs}}} \mathrm{h}^{b_{\mathrm{zs}}} \mathrm{m}^{-3}\right)$ of the analytical $Z_{e^{-}} S$ relationship for the MRR for the case study at Ny-Ålesund on 7 Feb 2018.

$35 \mathrm{GHz}$ to retrieve snowfall rate from MRR reflectivities. An actual relationship for the 24-GHz MRR has recently been derived by S17 who also used a PIP instrument, but at the Princess Elisabeth Station in East Antarctica, where snow particles are smaller than at northern midlatitudes. KB09 and M07 also derived $Z_{e}-S$ relationships for $94 \mathrm{GHz}$ radars, which we applied to the MiRAC-A reflectivities.

To differentiate between the different relationships for the different frequencies, we use the notation, for example, M07_K and M07_W, to indicate which $Z_{e}-S$ relationship is applied to MRR and MiRAC-A reflectivities, respectively. Furthermore, since KB09 derived three relations for different particle shapes from idealized models that represent unrimed ice particles best and thus dry snowfall, we abbreviate the various ice particle models used in KB09 as follows: aggregates (KB09ag), threebullet rosettes (KB09br), and low-density spherical snow particles (KB09sp). M07 derived the $Z_{e}-S$ relationships from nonspherical aggregate and single crystal dendrite snow particle models for dry snowfall. The dataset from Hyytiälä consists of a mixture of snow particles, that is, single crystals, low density, and rimed aggregates. Meteorological conditions seem to favor riming process in Hyytiälä when derived snowfall masses are compared to model simulations (Tyynelä and von Lerber 2019). Moisseev et al. (2017) demonstrated during the winter of $2014 / 15$ that riming is responsible for $5 \%-40 \%$ of snowfall mass.

The values of the prefactor $a_{\mathrm{zs}}$ for our derived relationship ANA_K differ between 59.25 and 2119.06 with a mean of 318.65. In comparison with the relationships from the literature applied to MRR reflectivities the $a_{\mathrm{zs}}$ values differ only between 18 and 313. The instantaneous values of $a_{\mathrm{zs}}$ throughout the day can be seen in Fig. 6 and show a large fluctuation especially for the times when we generally have more liquid water in the atmosphere (between 1500 and 2300 UTC). These swings are a physical signal, as they describe the large changes in $N_{0}$. This large spread in $a_{\mathrm{zs}}$ values underlines the need for a changing parameter rather than a constant prefactor. The latter does not capture the variability of the snowfall properties, which vary with time.

The application of the different $Z_{e}-S$ relationships from the literature results in large variations in snowfall rate for the present case study (Figs. 7a). The accumulated snowfall from all relationships during this day ranges between 3 and $33 \mathrm{~mm}$ (Figs. 7b) with the total accumulation amounts listed in Table 2. One would have expected that the relationships from the literature for the same particle types, but different frequencies would result in a similar snowfall rate. For example, the time series of the snowfall rate as well as of the accumulated snowfall until about 1900 UTC reveal that the relations by S17_K and KB09sp_W agree surprisingly well, but the accumulation calculated with KB09sp_K has $8.64 \mathrm{~mm}$ less than the amount of KB09sp_W. If we take Pluvio as the observational reference for the snow accumulation, most of the relationships from the literature show a far too high accumulated snowfall (up to almost $30 \mathrm{~mm}$ difference).

To have a closer look on the derived relationships in this study we compare them to the relationships from the literature that fit more closely to Pluvio measurements, namely KB09ag_K and KB09ag_W. An enlarged view onto these four relationships can be seen in Fig. 8. The temporal developments of the snowfall rate computed with ANA_K and AVE_W agree very well with each other within their displayed uncertainty range. Also, the snowfall rates from KB09ag_K and KB09ag_W are most of the time within this uncertainty range. With regard to the snowfall accumulation, the amount between ANA_K and AVE_W differs by $0.33 \mathrm{~mm}$, only, whereas KB09ag_K and KB09ag_W differ by $1.78 \mathrm{~mm}$. Relative to Pluvio, KB09ag_K shows the smallest difference of $1.13 \mathrm{~mm}$ (19\%). ANA_K and AVE_W have a difference of $1.19 \mathrm{~mm}$

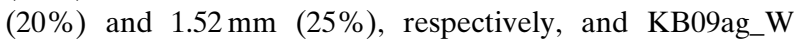
shows the largest difference of $2.91 \mathrm{~mm}(49 \%)$. From this case study, we can draw several conclusions: First, we show that the geographical differences in the radar-based snowfall intensity estimates, often reported in the literature, can be reduced by taking into account changes in the PSD intercept parameter $N_{0}$. Therefore, a combination of a radar and a disdrometer can be used for quantitative snowfall measurements and retrievals. The retrieval method is not too sensitive to a geographical location. This is demonstrated by developing $Z_{e}-S$ relations using data from Hyytiälä and applying them to the observations at Ny-Ålesund. We also show that the uncertainty of $Z_{e^{-}}$ $S$-based snowfall estimates depend on radar frequency. For snowfall intensity estimates based on W-band radar observations, the $Z_{e}-S$ relation adjustment by using the PSD intercept 

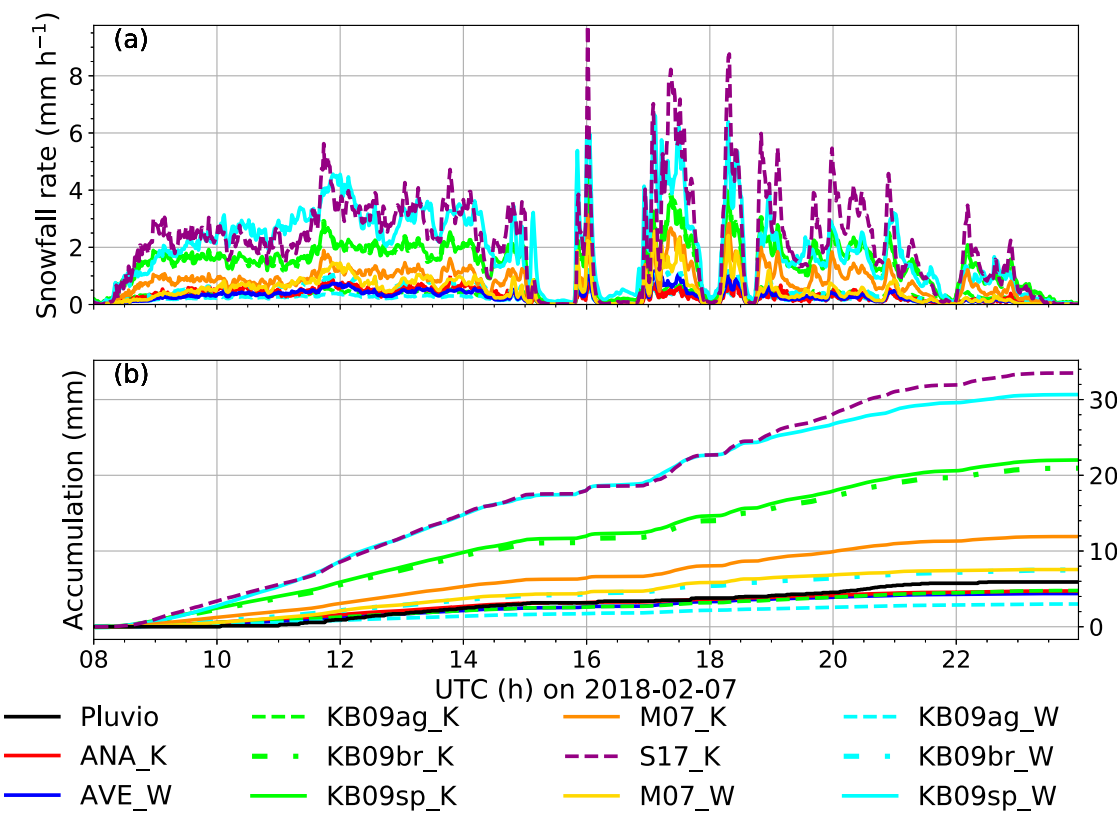

FIG. 7. (a) Snowfall rate $\left(\mathrm{mm} \mathrm{h}^{-1}\right)$ at Ny-Ålesund on 7 Feb 2018 from the two methods developed in this study for the W-band radar MiRAC-A (AVE_W) and for the K-band radar MRR (ANA_K), as well as nine $Z_{e}-S$ relationships from the literature-five for MRR and four for MiRAC-A. The abbreviated forms in KB09 are the representative ice models used for the snowfall-rate retrieval: ag = aggregates; $\mathrm{br}=$ three-bullet rosettes, and $\mathrm{sp}=$ low-density spherical snow particles for K-band and W-band radar, indicated by _K or _W, respectively. (b) Accumulated snowfall ( $\mathrm{mm}$ ) from the same relationships as in (a) and additionally from the observational reference Pluvio.

parameter seems to be unnecessary. Furthermore, it is shown that by comparing snowfall intensity estimates using data from radars operating at different frequencies, that is, $\mathrm{K}$ and $\mathrm{W}$ band, potential instrumental errors can be diagnosed. To achieve this, however, the snowfall rate calculated with $Z_{e}-S$ relations for different radar frequencies should be consistent between each other, that is, relying on the same assumptions and retrieval uncertainties should also be known. It appears that the $Z_{e}-S$ relationships from the literature, at least those discussed in this study, show a large variability and are not necessarily consistent with each other throughout the used frequency range, even when the same particle type assumption is used.

To gain a higher confidence in our method, we analyzed two further case studies for Ny-Ålesund for 16 March and 16 April 2018 (Figs. 9-12, Table 3). Also for these cases, ANA_K and AVE_W show a similar temporal development of the snowfall rate and agree very well within their uncertainty range. Their accumulation difference to the observational reference Pluvio is small: on 16 March 2018, the differences are $+0.73 \mathrm{~mm}(36 \%)$ for AVE_W and $+1.84 \mathrm{~mm}(92 \%)$ for ANA_K (Fig. 10). On 16 April 2018, the snowfall accumulation is underestimated by $0.35 \mathrm{~mm}(19 \%)$ by $0.35 \mathrm{~mm}(19 \%)$ by ANA_K and $0.54 \mathrm{~mm}(29 \%)$ by AVE_W (Fig. 12). The closest relationships from the literature are similar as for 7 February 2018, KB09ag_K and KB09ag_W as well as M07_W (Table 3). The difference of snowfall amounts from the other $Z_{e}-S$ relationships from the literature compared to Pluvio are much higher. They overestimate the snowfall accumulation by
2-20 mm (100\%-992\%) on 16 March and by $0.8-9 \mathrm{~mm}(43 \%-$ $476 \%)$ on 16 April 2018.

S17 and KB09sp_W are in all case studies the two relationships that show the largest differences in snowfall accumulation compared to Pluvio. Note that temperature, wind speed, and LWP are different for both days (Figs. 10 and 11). For 16 March 2018, temperatures are well below zero and LWP is much lower than for 7 February 2018. The wind speeds are less than $3 \mathrm{~m} \mathrm{~s}^{-1}$ throughout most of the day with values of up to $10 \mathrm{~m} \mathrm{~s}^{-1}$ at the beginning and end of the day. The latter could have led to a delayed onset of snowfall detection by Pluvio that can be seen in the accumulated snowfall (Fig. 10). Nevertheless, as mentioned before, differences between snowfall amounts of Pluvio and of ANA_K and AVE_W are small compared to most of the differences in snowfall amount related to the various $Z_{e}-S$ relationships from the literature. On 16 April 2018, temperatures are just above $0^{\circ} \mathrm{C}$ and thus higher compared to the other two cases. The wind speed is very low, with values below $2 \mathrm{~m} \mathrm{~s}^{-1}$ most of the time. For completeness, the $a_{\mathrm{zs}}$ values (not shown) for $\mathrm{K}$ band ranged between 31 and 1235 with a mean of 215 on 16 March 2018. On 16 April 2018, $a_{\mathrm{zs}}$ values range from 103 to 1898 with a mean of 340 .

\section{Summary and outlook}

Two $Z_{e}-S$ relationships for $\mathrm{K}$ - and $\mathrm{W}$-band radars, respectively, have been developed in this study. For the W-band 

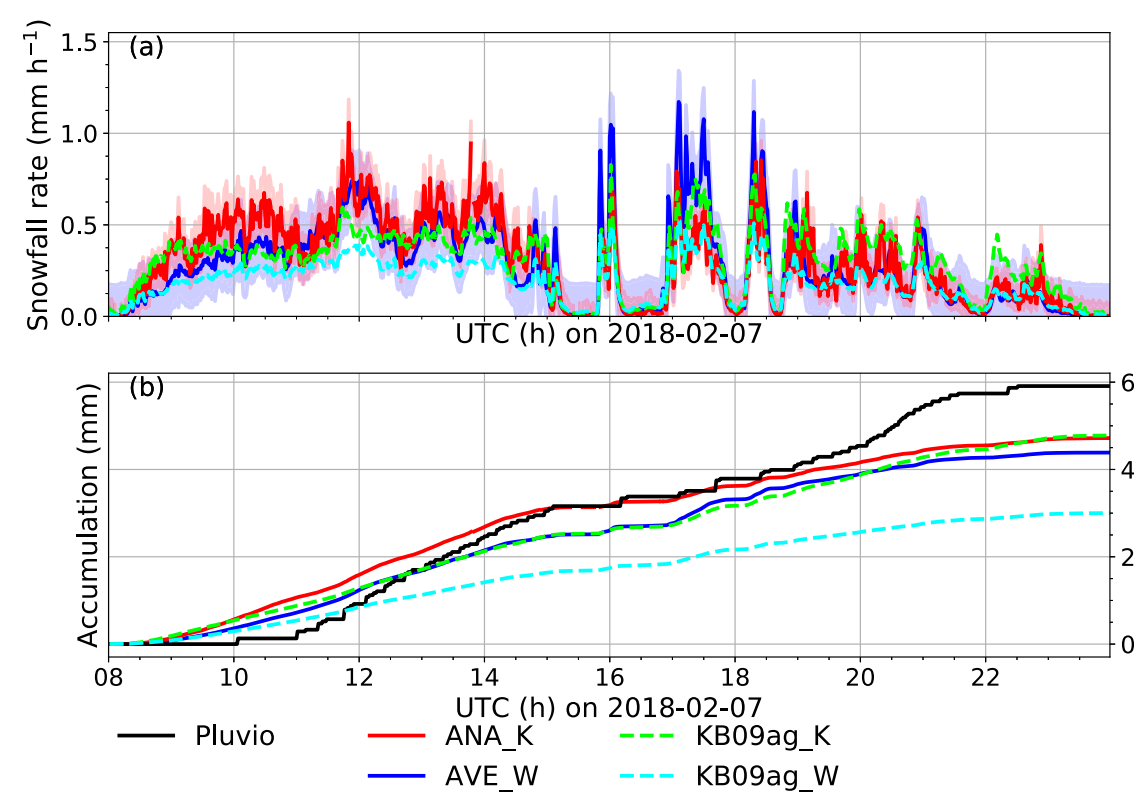

FIG. 8. As in Fig. 7, but zooming in on the methods developed in this study. The uncertainty of the snowfall rate of AVE_W and ANA_K is indicated by the blue and red shading, respectively. Two relationships from the literature, i.e., KB09ag_K and KB09ag_W, are shown as well (see caption of Fig. 7 for further details).

radar, a common approach with constant parameters, here called average relationship, is applied. For the K-band radar, we used an analytical method in which the prefactor $a_{\mathrm{zs}}$ is kept variable in time and depends on the PSD intercept parameter $N_{0}$. This method is new and has not been applied yet for snowfall-rate retrievals.
Especially at higher latitudes and in the Arctic due to its fastchanging climate, the observation of snowfall is crucial to examine. Surface instrumentation such as a precipitation gauge is prone to undercatchment and the $\mathrm{W}$-band radar on the satellite CloudSat is unreliable within its blind zone (closest $1200 \mathrm{~m}$ toward the ground) (Maahn et al. 2014), where some of the

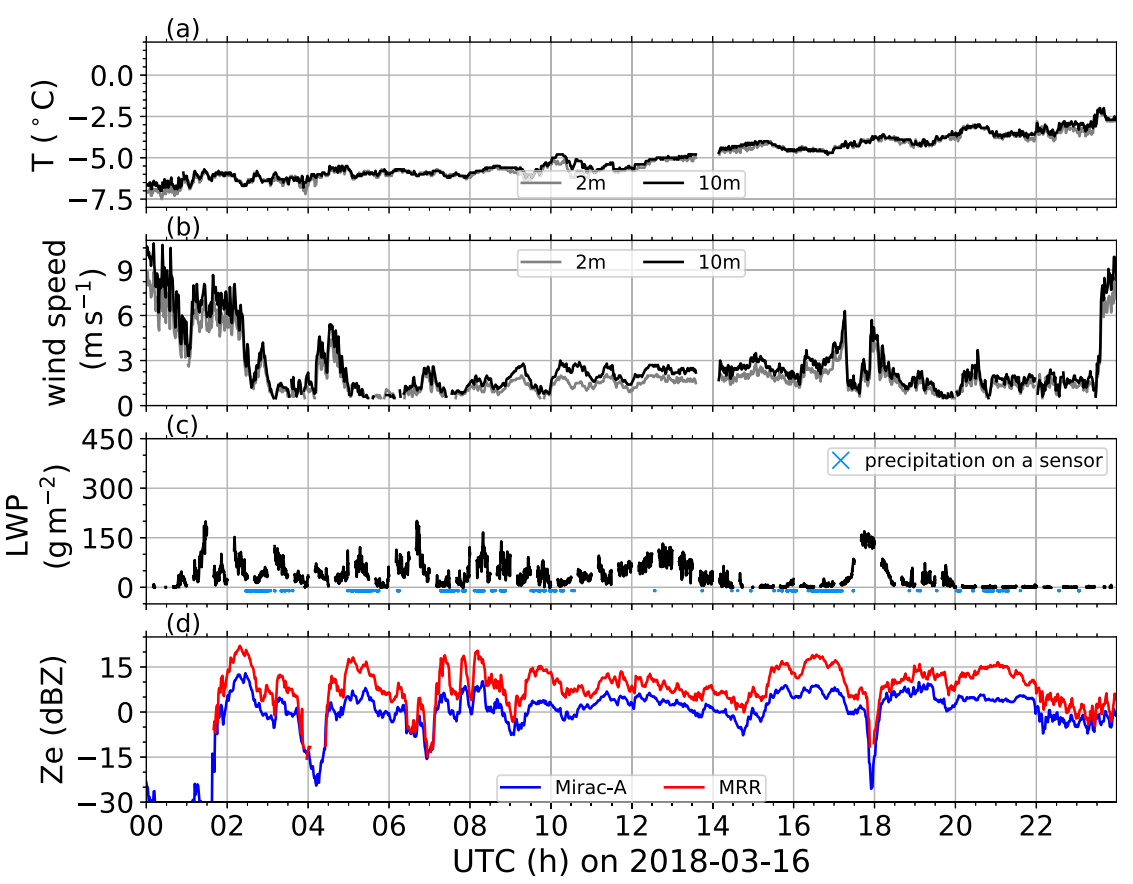

FIG. 9. As in Fig. 5, but for 0000-2359 UTC 16 Mar 2018. 

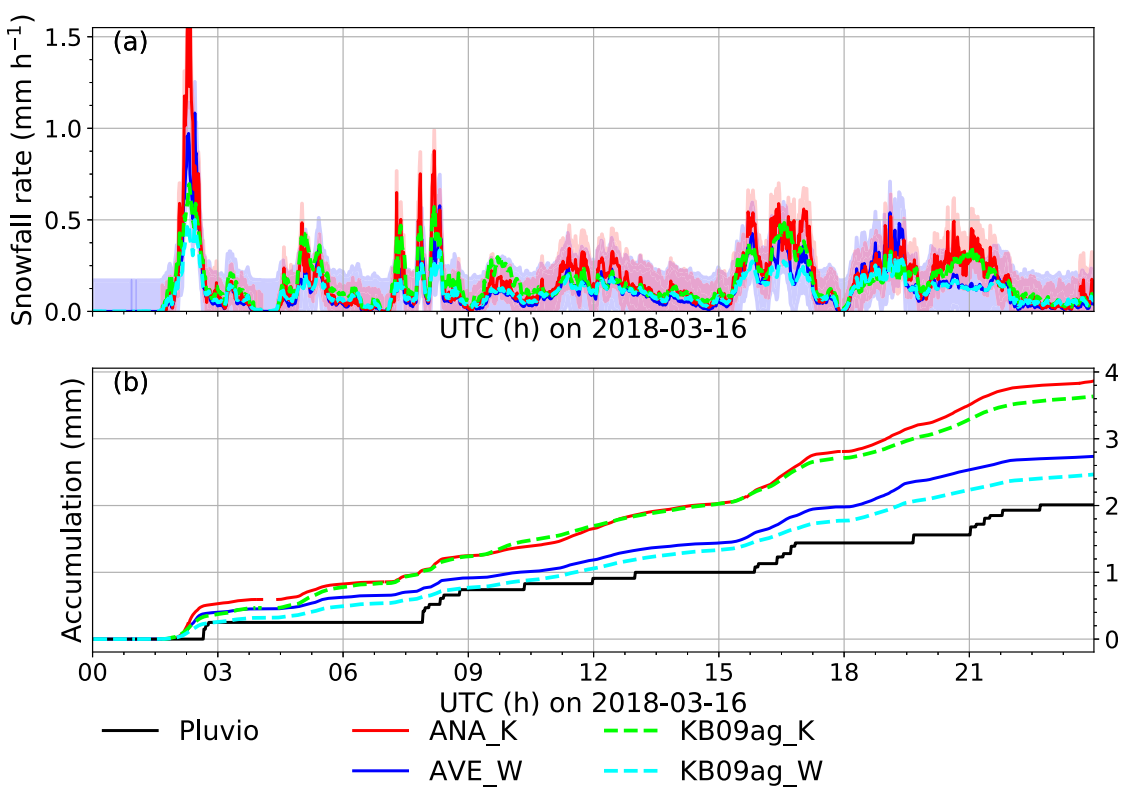

FIG. 10. As in Fig. 8, but for 0000-2359 UTC 16 Mar 2018.

shallow snowfall is forming (Kulie et al. 2016; Kulie and Milani 2018).

The ground-based MRR, measuring in the $\mathrm{K}$ band, is more and more used at different sites including Antarctica and has recently been installed at the AWIPEV Arctic Research Base in Ny-Ålesund together with the W-band cloud radar MiRAC-A. In this study, we introduced a method with which it is possible to operationally retrieve snowfall rates from MRR measurements. Additionally, we can increase the confidence in the
MRR retrieved snowfall rates by comparing them to snowfall rates retrieved from the reflectivities of the parallel in time operating MiRAC-A and to Pluvio measurements. We use the Pluvio as the in situ observational reference. To develop $Z_{e}-S$ relationships, detailed in situ observations of snowfall particles are needed, which are unfortunately not available at AWIPEV. We have thus used snowfall measurements (fall velocity, particle size distribution, and mass) from the video-disdrometer PIP at the measurement site in Hyytiälä, Finland. With these variables we

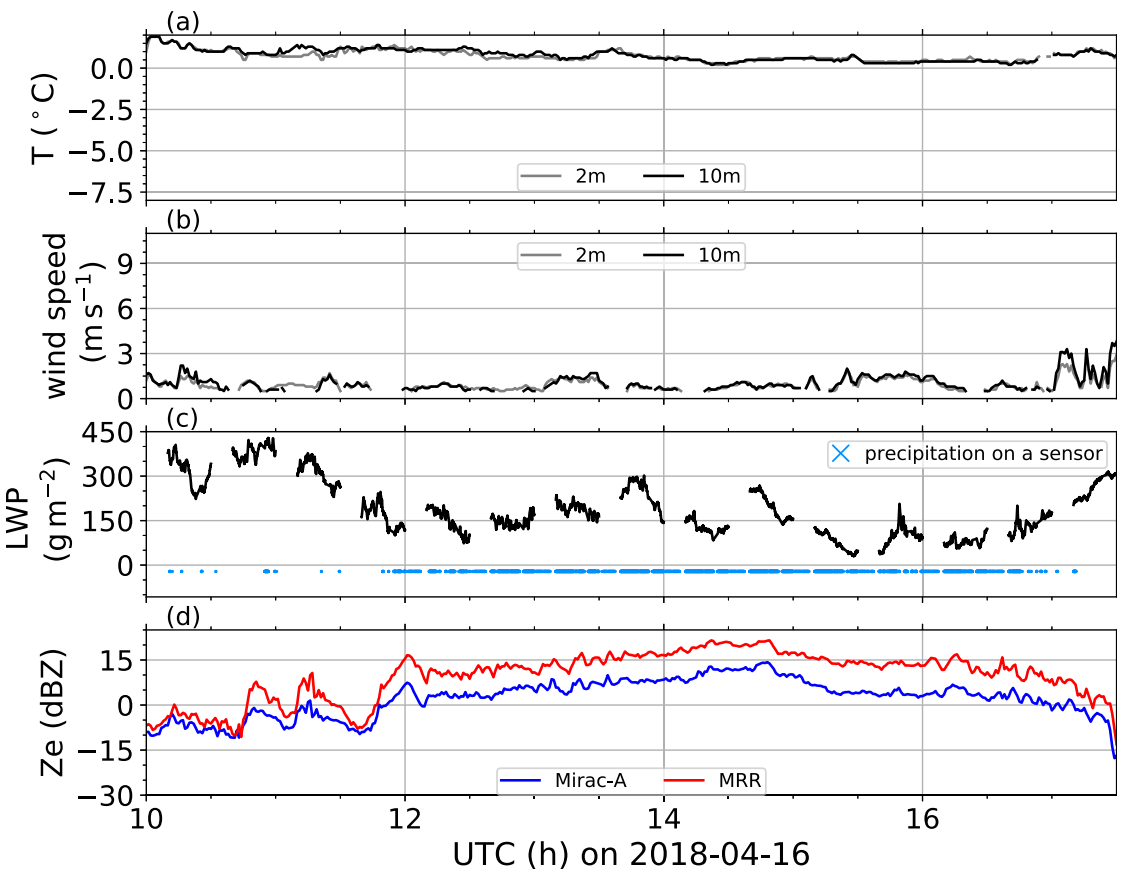

FIG. 11. As in Fig. 5, but for 1000-1730 UTC 16 Apr 2018. 

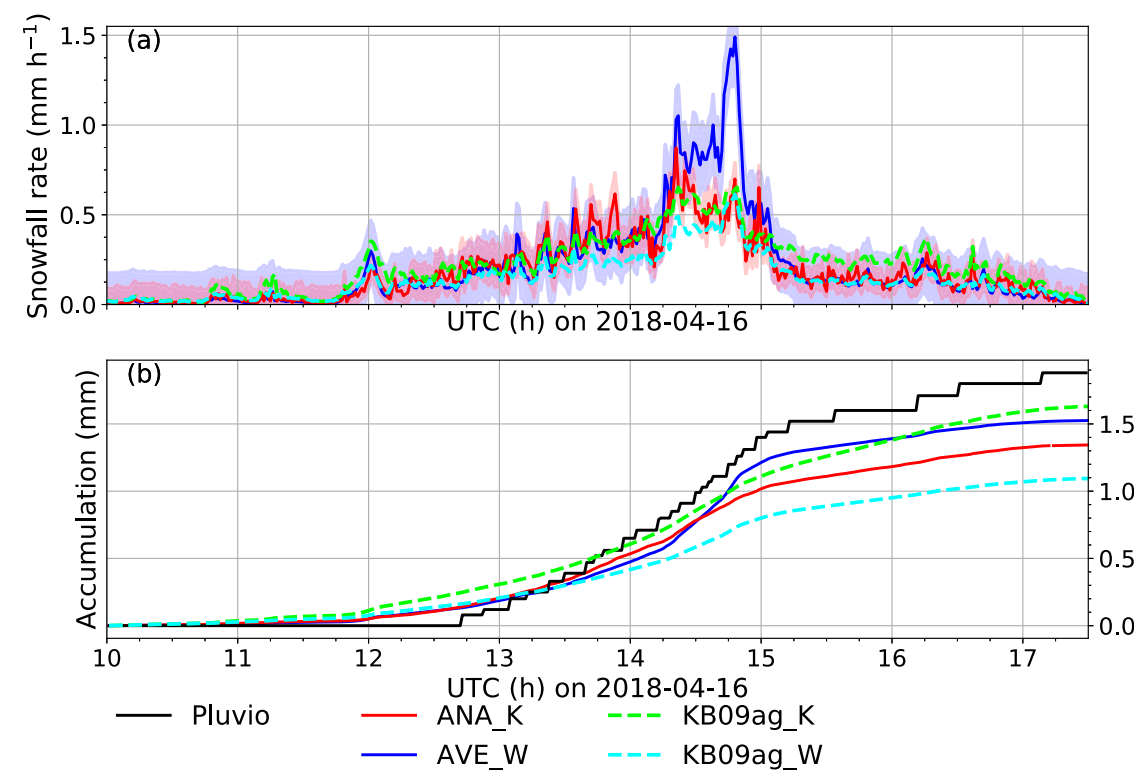

FIG. 12. As in Fig. 8, but for 1000-1730 UTC 16 Apr 2018.

were able to calculate snowfall rates and simulate reflectivity values at $\mathrm{K}$ and $\mathrm{W}$ band, respectively. Based on this dataset, the two different $Z_{e}-S$ relationships, that is, the more common approach with constant parameters and the new analytical approach with time- and $N_{0}$-dependent prefactor $a_{\mathrm{zs}}$, were developed.

An uncertainty analysis revealed that the new approach strongly reduces the uncertainty for snowfall rates calculated with K-band reflectivities by more than half, from 0.37 to $0.11 \mathrm{~mm} \mathrm{~h}^{-1}$. The uncertainty for the snowfall rates from the $\mathrm{W}$-band $Z_{e}-S$ relationships only differed by $0.01 \mathrm{~mm} \mathrm{~h}^{-1}$. Thus, for $\mathrm{W}$ band, the average $Z_{e}-S$ relationship is favored over the more complex analytical $Z_{e}-S$ relationship.

To test the performance of the developed relationships, we applied the analytical $Z_{e}-S$ relationship to measured reflectivity values of the MRR (ANA_K) and the average $Z_{e}-S$ relationship to MiRAC-A reflectivities (AVE_W) in Ny-Ålesund for a case study on 7 February 2018. Low wind conditions on this day facilitated a comparison of the snowfall accumulation from the radar with the precipitation gauge Pluvio. In addition, we compared snowfall rates retrieved with different $Z_{e}-S$ relationships from literature with the snowfall rates calculated from our methods.

A large spread in the total accumulated snowfall values of the $Z_{e}-S$ relationships from the literature shows the difficulty of just applying any $Z_{e}-S$ relationship to reflectivity values at any location. Our results show that a relationship that has been developed for Antarctica (S17) might not be appropriate for the Arctic site in Ny-Ålesund. The $Z_{e}-S$ relationship (S17) revealed the largest differences in snowfall rate and snowfall accumulation (about $30 \mathrm{~mm}$ ) relative to Pluvio and our developed methods. One possible reason for this difference could be that particle types and also the PSD in Antarctica are quite different to the particle types and PSD in Ny-Ålesund. However, more detailed information on particle masses and types of the snowfall would be needed at Ny-Ålesund to have a closer look on the snow characteristics.

For the case study analyzed, we could show that the newly developed $Z_{e}-S$ relationships ANA_K and AVE_W agree well with the observational reference and also well with each other within their uncertainty range. The accumulated snowfall on 7 February 2018 derived with ANA_K and AVE_W is only $1.19 \mathrm{~mm} \mathrm{(20 \% )}$ and $1.52 \mathrm{~mm}(25 \%)$, respectively, less than the accumulated snowfall amount from Pluvio $(5.91 \mathrm{~mm})$. This matching also indicates that the snowfall conditions at $\mathrm{Ny}$ Ålesund are likely similar to the ones at Hyytiälä. When including further $Z_{e}-S$ relationships from literature in the analysis, the corresponding retrieved accumulated snowfall values differ from the Pluvio snowfall amount by $19 \%-467 \%$. Only two of the applied relationships from the literature, that is, KB09ag_K and KB09ag_W, show a similar good performance as ANA_K and AVE_W.

TABLE 3. Accumulated snowfall (mm) at $\mathrm{Ny}$-Ålesund on 16 Mar and 16 Apr 2018 from the observational reference Pluvio and from the same $Z_{e}-S$ relationships as shown in Table 2 using MRR (K band) and MiRAC-A (W band) reflectivity measurements.

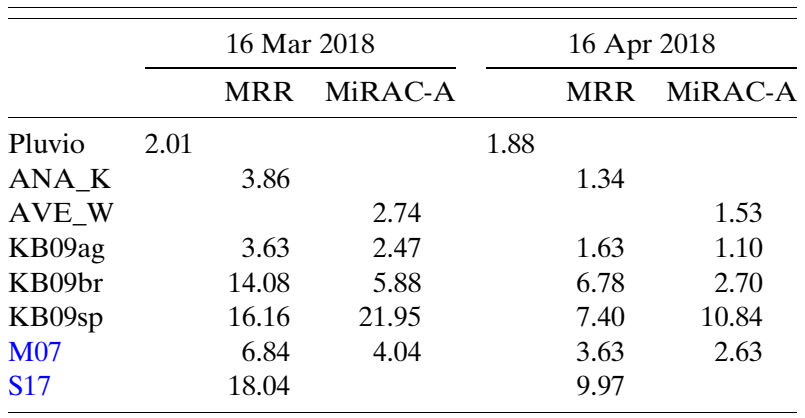


An analysis of two further case studies at Ny-Ålesund with different meteorological conditions also showed good results for both the temporal development of the snowfall rate as well as the snowfall accumulation relative to the observational reference. An analysis of a longer time period of snowfall measurements is necessary to be able to provide more robust statistics and will be one of the next steps. The application to the long-term data at $\mathrm{Ny}$-Ålesund, however, is difficult and bears other uncertainties such as the discrimination between liquid and solid precipitation in the first place and using additional correction equations for Pluvio to account for precipitation losses in high wind conditions.

In addition to the application of the newly developed $Z_{e}-S$ relationships to the measurements at $\mathrm{Ny}$-Ålesund, also the MRR measurements as part of the Cold-Air Outbreaks in the Marine Boundary Layer Experiment (COMBLE; December 2019-May 2020) on Bear Island, Svalbard, will be analyzed in more detail and snowfall rates estimated. In this way, we will gain further insight into the spatial variability of precipitation in Svalbard and also show the broader applicability of our method. In this respect, we have also recently applied the newly developed K-band $Z_{e}-S$ relationship to measurements of a site in Marquette, Michigan, where MRR measurements with collocated PIP observations were available (Pettersen et al. 2020). Those results (not shown) are promising and will be investigated in more detail in the future.

Acknowledgments We gratefully acknowledge the funding by the Deutsche Forschungsgemeinschaft (DFG, German Research Foundation)_Project-ID 268020496-TRR 172, within the Transregional Collaborative Research Center Arctic Amplification: Climate Relevant Atmospheric and Surface Processes, and Feedback Mechanisms (AC) ${ }^{3}$. We thank the AWIPEV team for their support in the operation of our instruments at AWIPEV and Christoph Ritter for providing the HATPRO measurements. We thank the personnel of Hyytiälä station and Matti Leskinen for their support in field observation. We appreciate the comments by the three anonymous reviewers.

Data availability statement. The meteorological surface BSRN observations are available from PANGAEA (Maturilli 2018). The MWR LWP data can also be downloaded from PANGAEA (Nomokonova et al. 2019b). The first two years of the PIP data are available at https://zenodo.org/record/3977959 (Moisseev 2020). The MRR, MiRAC-A, Pluvio, and PARSIVEL measurements of the case studies are available at https://doi.org/ 10.5281/zenodo.4017348 (Ebell 2020).

\section{REFERENCES}

Battaglia, A., E. Rustemeier, A. Tokay, U. Blahak, and C. Simmer, 2010: PARSIVEL snow observations: A critical assessment. J. Atmos. Oceanic Technol., 27, 333-344, https://doi.org/ 10.1175/2009JTECHA1332.1.

Boggs, P. T., and J. E. Rogers, 1990: Orthogonal distance regression. Statistical Analysis of Measurement Error Models and Applications: Proc. AMS-IMS-SIAM Joint Summer Research Conf., Arcata, CA, American Mathematical Society, 183-194.
— R. H. Byrd, J. E. Rogers, and R. B. Schnabel, 1992: User's reference guide for ODRPACK version 2.01: Software for weighted orthogonal distance regression. Accessed 30 August 2019, https://docs.scipy.org/doc/external/odrpack_guide.pdf.

Bruggeman, D. A. G., 1935: Berechnung verschiedener physikalischer Konstanten von heterogenen Substanzen. I. Dielektrizitätskonstanten und Leitfähigkeiten der Mischkörper aus isotropen Substanzen. Ann. Phys., 416, 636-664, https:// doi.org/10.1002/andp.19354160705.

Carlson, P. E., and J. S. Marshall, 1972: Measurement of snowfall by radar. J. Appl. Meteor., 11, 494-500, https://doi.org/10.1175/ 1520-0450(1972)011<0494:MOSBR>2.0.CO;2.

Chase, R. J., S. W. Nesbitt, and G. M. McFarquhar, 2020: Evaluation of the microphysical assumptions within GPMDPR using ground-based observations of rain and snow. Atmosphere, 11, 619, https://doi.org/10.3390/atmos11060619.

Ebell, K., 2020: Cloud radar, Micro Rain Radar, Parsivel and Pluvio measurements at Ny-Ålesund for 7 Feb 2018, 16 March 2018 and 16 April 2018. Zenodo, https://doi.org/10.5281/ zenodo.4017348.

Falconi, M. T., A. Lerber, D. Ori, F. S. Marzano, and D. Moisseev, 2018: Snowfall retrieval at X, Ka and W bands: Consistency of backscattering and microphysical properties using BAECC ground-based measurements. Atmos. Meas. Tech., 11, 30593079, https://doi.org/10.5194/amt-11-3059-2018.

Førland, E. J., R. Benestad, I. Hanssen-Bauer, J. E. Haugen, and T. E. Skaugen, 2011: Temperature and precipitation development at Svalbard 1900-2100. Adv. Meteor., 2011, 893790, https://doi.org/10.1155/2011/893790.

Fujiyoshi, Y., T. Endoh, T. Yamada, K. Tsuboki, Y. Tachibana, and G. Wakahama, 1990: Determination of a $Z-R$ relationship for snowfall using a radar and high sensitivity snow gauges. J. Appl. Meteor., 29, 147-152, https://doi.org/10.1175/15200450(1990)029<0147:DOARFS > 2.0.CO;2.

Hari, P., and M. Kulmala, 2005: Station for Measuring EcosystemAtmosphere Relations: SMEAR. Boreal Environ. Res., 10, 315-322.

Heymsfield, A. J., S. Y. Matrosov, and N. B. Wood, 2016: Toward improving ice water content and snow-rate retrievals from radars. Part I: X and W bands, emphasizing CloudSat. J. Appl. Meteor. Climatol., 55, 2063-2090, https://doi.org/10.1175/ JAMC-D-15-0290.1.

Huang, G.-J. J., V. N. Bringi, R. Cifelli, D. Hudak, and W. A. Petersen, 2010: A methodology to derive radar reflectivityliquid equivalent snow rate relations using $\mathrm{C}$-band radar and a 2D video disdrometer. J. Atmos. Oceanic Technol., 27, 637651, https://doi.org/10.1175/2009JTECHA1284.1.

IPCC, 2007: Climate Change 2007: The Physical Science Basis. Cambridge University Press, 996 pp.

Klugmann, D., K. Heinsohn, and H. J. Kirtzel, 1996: A low cost $24 \mathrm{GHz}$ FM-CW Doppler radar rain profiler. Contrib. Atmos. Phys., 69, 247-253.

Kneifel, S., M. Maahn, G. Peters, and C. Simmer, 2011: Observation of snowfall with a low-power FM-CW K-band radar (Micro Rain Radar). Meteor. Atmos. Phys., 113, 75-87, https://doi.org/10.1007/ s00703-011-0142-z.

— A. Lerber, J. Tiira, D. Moisseev, P. Kollias, and J. Leinonen, 2015: Observed relations between snowfall microphysics and triple-frequency radar measurements. J. Geophys. Res. Atmos., 120, 6034-6055, https://doi.org/10.1002/2015JD023156.

Kollias, P., E. E. Clothiaux, M. A. Miller, B. A. Albrecht, G. L. Stephens, and T. P. Ackerman, 2007: Millimeter-wavelength radars: New frontier in atmospheric cloud and precipitation 
research. Bull. Amer. Meteor. Soc., 88, 1608-1624, https:// doi.org/10.1175/BAMS-88-10-1608.

Küchler, N., S. Kneifel, U. Löhnert, P. Kollias, H. Czekala, and T. Rose, 2017: A W-band radar-radiometer system for accurate and continuous monitoring of clouds and precipitation. J. Atmos. Oceanic Technol., 34, 2375-2392, https://doi.org/ 10.1175/JTECH-D-17-0019.1.

Kulie, M. S., and R. Bennartz, 2009: Utilizing spaceborne radars to retrieve dry snowfall. J. Appl. Meteor. Climatol., 48, 25642580, https://doi.org/10.1175/2009JAMC2193.1.

—_, and L. Milani, 2018: Seasonal variability of shallow cumuliform snowfall: A CloudSat perspective. Quart. J. Roy. Meteor. Soc., 144, 329-343, https://doi.org/10.1002/qj.3222.

,,-- N. B. Wood, S. A. Tushaus, R. Bennartz, and T. S. L'Ecuyer, 2016: A shallow cumuliform snowfall census using spaceborne radar. J. Hydrometeor., 17, 1261-1279, https:// doi.org/10.1175/JHM-D-15-0123.1.

Langille, R. C., and R. S. Thain, 1951: Some quantitative measurements of three-centimeter radar echoes from falling snow. Can. J. Phys., 29, 482-490, https://doi.org/10.1139/p51-052.

Leinonen, J., 2014: High-level interface to T-matrix scattering calculations: Architecture, capabilities and limitations. Opt. Express, 22, 1655-1660, https://doi.org/10.1364/OE.22.001655.

_ 2018: Python code for T-matrix scattering calculations. Accessed 24 August 2018, https://github.com/jleinonen/pytmatrix/.

_ , and D. Moisseev, 2015: What do triple-frequency radar signatures reveal about aggregate snowflakes? J. Geophys. Res. Atmos., 120, 229-239, https://doi.org/10.1002/2014JD022072.

—_, and W. Szyrmer, 2015: Radar signatures of snowflake riming: A modeling study. Earth Space Sci., 2, 346-358, https://doi.org/ 10.1002/2015EA000102.

__, S. Kneifel, D. Moisseev, J. Tyynelä, S. Tanelli, and T. Nousiainen, 2012: Evidence of nonspheroidal behavior in millimeter-wavelength radar observations of snowfall. J. Geophys. Res., 117, D18205, https://doi.org/10.1029/ 2012JD017680.

_ properties from multifrequency radar observations. Atmos. Meas. Tech., 11, 5471-5488, https://doi.org/10.5194/amt-11-5471-2018.

Levizzani, V., S. Laviola, and E. Cattani, 2011: Detection and measurement of snowfall from space. Remote Sens., 3, 145166, https://doi.org/10.3390/rs3010145.

Lhermitte, R., 1987: A 94-GHz doppler radar for cloud observations. J. Atmos. Oceanic Technol., 4, 36-48, https://doi.org/ 10.1175/1520-0426(1987)004<0036:AGDRFC>2.0.CO;2.

_ 1988: Observation of rain at vertical incidence with a $94 \mathrm{GHz}$ Doppler radar: An insight on Mie scattering. Geophys. Res. Lett., 15, 1125-1128, https://doi.org/10.1029/GL015i010p01125.

Li, H., D. Moisseev, and A. von Lerber, 2018: How does riming affect dual-polarization radar observations and snowflake shape? J. Geophys. Res. Atmos., 123, 6070-6081, https:// doi.org/10.1029/2017JD028186.

López-Moreno, J. I., J. Boike, A. Sanchez-Lorenzo, and J. W. Pomeroy, 2016: Impact of climate warming on snow processes in Ny-Ålesund, a polar maritime site at Svalbard. Global Planet. Change, 146, 10-21, https://doi.org/10.1016/ j.gloplacha.2016.09.006.

Maahn, M., and P. Kollias, 2012: Improved Micro Rain Radar snow measurements using Doppler spectra post-processing. Atmos. Meas. Tech., 5, 2661-2673, https://doi.org/10.5194/amt-5-26612012.

—, C. Burgard, S. Crewell, I. V. Gorodetskaya, S. Kneifel, S. Lhermitte, K. Van Tricht, and N. P. M. van Lipzig, 2014:
How does the spaceborne radar blind zone affect derived surface snowfall statistics in polar regions? J. Geophys. Res. Atmos., 119, 13 604-13 620, https://doi.org/10.1002/2014JD022079.

Mason, S. L., C. J. Chiu, R. J. Hogan, D. Moisseev, and S. Kneifel, 2018: Retrievals of riming and snow density from vertically pointing Doppler radars. J. Geophys. Res. Atmos., 123, 13 80713 834, https://doi.org/10.1029/2018JD028603.

_ L. von Terzi, 2019: The importance of particle size distribution and internal structure for triple-frequency radar retrievals of the morphology of snow. Atmos. Meas. Tech., 12, 4993-5018, https://doi.org/10.5194/amt-12-4993-2019.

Matrosov, S. Y., 2007: Modeling backscatter properties of snowfall at millimeter wavelengths. J. Atmos. Sci., 64, 1727-1736, https://doi.org/10.1175/JAS3904.1.

— M. D. Shupe, and I. V. Djalalova, 2008: Snowfall retrievals using millimeter-wavelength cloud radars. J. Appl. Meteor. Climatol., 47, 769-777, https://doi.org/10.1175/2007JAMC1768.1.

Maturilli, M., 2018: Continuous meteorological observations at station Ny-Ålesund (2018-02). PANGAEA, accessed 1 June 2019, https://doi.org/10.1594/PANGAEA.894665.

- A. Herber, and G. König-Langlo, 2013: Climatology and time series of surface meteorology in Ny-Ålesund, Svalbard. Earth Syst. Sci. Data, 5, 155-163, https://doi.org/10.5194/essd-5-155-2013.

Mech, M., L.-L. Kliesch, A. Anhäuser, T. Rose, P. Kollias, and S. Crewell, 2019: Microwave Radar/Radiometer for Arctic Clouds (MiRAC): First insights from the ACLOUD campaign. Atmos. Meas. Tech., 12, 5019-5037, https://doi.org/ 10.5194/amt-12-5019-2019.

Mishchenko, M. I., and L. D. Travis, 1994: T-matrix computations of light scattering by large spheroidal particles. Opt. Commun., 109, 16-21, https://doi.org/10.1016/0030-4018(94) 90731-5.

Mitchell, D. L., and A. J. Heymsfield, 2005: Refinements in the treatment of ice particle terminal velocities, highlighting aggregates. J. Atmos. Sci., 62, 1637-1644, https://doi.org/10.1175/ JAS3413.1.

Moisseev, D., 2020: dmoisseev/Snow-Retrievals-2014-2015: Snowfalke mass retrievals 2014/2015. Zenodo, https://doi.org/10.5281/ zenodo.3977959.

- and V. Chandrasekar, 2007: Examination of the $\mu-\Lambda$. J. Atmos. Oceanic Technol., 24, 847-855, https://doi.org/ 10.1175/JTECH2010.1.

_ A. von Lerber, and J. Tiira, 2017: Quantifying the effect of riming on snowfall using ground-based observations. J. Geophys. Res. Atmos., 122, 4019-4037, https://doi.org/10.1002/2016JD026272.

Newman, A. J., P. A. Kucera, and L. F. Bliven, 2009: Presenting the Snowflake Video Imager (SVI). J. Atmos. Oceanic Technol., 26, 167-179, https://doi.org/10.1175/2008JTECHA1148.1.

Nomokonova, T., K. Ebell, U. Löhnert, M. Maturilli, C. Ritter, and E. O'Connor, 2019a: Statistics on clouds and their relation to thermodynamic conditions at Ny-Ålesund using ground-based sensor synergy. Atmos. Chem. Phys. Discuss., 19, 4105-4126, https://doi.org/10.5194/acp-19-4105-2019.

_, C. Ritter, and K. Ebell, 2019b: HATPRO microwave radiometer measurements at AWIPEV, Ny-Ålesund (2016-2018). PANGAEA, accessed 1 June 2019, https://doi.org/10.1594/ PANGAEA.902183.

OTT, 2016: Operating instructions: Precipitation gauge OTT Pluvio ${ }^{2}$ L. OTT Doc., 60 pp., https://www.ott.com/download/ operating-instructions-precipitation-gauge-ott-pluvio2-1-1/.

Pettersen, C., and Coauthors, 2020: The precipitation imaging package: Assessment of microphysical and bulk characteristics 
of snow. Atmosphere, 11, 785, https://doi.org/10.3390/ atmos11080785.

Rasmussen, R., M. Dixon, S. Vasiloff, F. Hage, S. Knight, J. Vivekanandan, and M. Xu, 2003: Snow nowcasting using a real-time correlation of radar reflectivity with snow gauge accumulation. J. Appl. Meteor., 42, 20-36, https://doi.org/ 10.1175/1520-0450(2003)042<0020:SNUART $>2.0$. CO;2.

- , and Coauthors, 2012: How well are we measuring snow: The NOAA/FAA/NCAR winter precipitation test bed. Bull. Amer. Meteor. Soc., 93, 811-829, https://doi.org/10.1175/ BAMS-D-11-00052.1.

Rasmussen, R. M., S. Landolt, B. Baker, J. Kochendorfer, B. Collins, M. Colli, L. Lanza, and J. Theriault, 2014: Examination of the performance of single Alter shielded and unshielded snow gauges using observations from the Marshall Field Site during the SPICE WMO Field Program and numerical model simulations. 17th Symp. on Meteorological Observation and Instrumentation, Westminster, CO, Amer. Meteor. Soc., 2.4, https:/ams.confex.com/ams/21Applied17SMOI/ webprogram/Paper247562.html.

Rose, T., S. Crewell, U. Löhnert, and C. Simmer, 2005: A network suitable microwave radiometer for operational monitoring of the cloudy atmosphere. Atmos. Res., 75, 183-200, https:// doi.org/10.1016/j.atmosres.2004.12.005.

Schrom, R. S., and M. R. Kumjian, 2018: Bulk-density representations of branched planar ice crystals: Errors in the polarimetric radar variables. J. Appl. Meteor. Climatol., 57, 333-346, https://doi.org/10.1175/JAMC-D-17-0114.1.

Serreze, M. C., and R. G. Barry, 2011: Processes and impacts of Arctic amplification: A research synthesis. Global Planet. Change, 77, 85-96, https://doi.org/10.1016/j.gloplacha.2011. 03.004 .

Sihvola, A., 1999: Electromagnetic Mixing Formulas and Applications. Institution of Electrical Engineers, 296 pp.

Souverijns, N., A. Gossart, S. Lhermitte, I. V. Gorodetskaya, S. Kneifel, M. Maahn, F. L. Bliven, and N. P. M. M. van Lipzig, 2017: Estimating radar reflectivity-snowfall rate relationships and their uncertainties over Antarctica by combining disdrometer and radar observations. Atmos. Res., 196, 211-223, https://doi.org/10.1016/j.atmosres.2017.06.001.

Stephens, G. L., and Coauthors, 2002: The CloudSat mission and the A-train. Bull. Amer. Meteor. Soc., 83, 1771-1790, https:// doi.org/10.1175/BAMS-83-12-1771.

- D. Winker, J. Pelon, C. Trepte, D. Vane, C. Yuhas, T. L'Ecuyer, and M. Lebsock, 2018: CloudSat and CALIPSO within the A-train: Ten years of actively observing the Earth system. Bull. Amer. Meteor. Soc., 99, 569-581, https://doi.org/ 10.1175/BAMS-D-16-0324.1.

Tiira, J., D. N. Moisseev, A. von Lerber, D. Ori, A. Tokay, L. F. Bliven, and W. Petersen, 2016: Ensemble mean density and its connection to other microphysical properties of falling snow as observed in southern Finland. Atmos. Meas. Tech., 9, 48254841, https://doi.org/10.5194/amt-9-4825-2016.

Tyynelä, J., and A. von Lerber, 2019: Validation of microphysical snow models using in situ, multifrequency, and dualpolarization radar measurements in Finland. J. Geophys. Res. Atmos., 124, 13273-13 290, https://doi.org/10.1029/ 2019JD030721.

_ J J. Leinonen, D. Moisseev, and T. Nousiainen, 2011: Radar backscattering from snowflakes: Comparison of fractal, aggregate, and soft spheroid models. J. Atmos. Oceanic Technol., 28, 1365-1372, https://doi.org/10.1175/JTECH-D-11-00004.1.

Ulbrich, C. W., and D. Atlas, 1998: Rainfall microphysics and radar properties: Analysis methods for drop size spectra. J. Appl. Meteor., 37, 912-923, https://doi.org/10.1175/1520-0450(1998) 037<0912:RMARPA $>2.0$. CO;2.

von Lerber, A., D. Moisseev, L. F. Bliven, W. Petersen, A.-M. M. Harri, and V. Chandrasekar, 2017: Microphysical properties of snow and their link to $Z_{e}-S$ relations during BAECC 2014. J. Appl. Meteor. Climatol., 56, 1561-1582, https://doi.org/ 10.1175/JAMC-D-16-0379.1.

—- —, D. A. Marks, W. Petersen, A.-M. Harri, and V. Chandrasekar, 2018: Validation of GMI snowfall observations by using a combination of weather radar and surface measurements. J. Appl. Meteor. Climatol., 57, 797820, https://doi.org/10.1175/JAMC-D-17-0176.1.

Wendisch, M., and Coauthors, 2017: Understanding causes and effects of rapid warming in the Arctic. Eos, Trans. Amer. Geophys. Union, 98, 22-26, https://doi.org/10.1029/2017EO064803.

—, and Coauthors, 2018: The Arctic cloud puzzle: Using ACLOUD/PASCAL multi-platform observations to unravel the role of clouds and aerosol particles in Arctic amplification. Bull. Amer. Meteor. Soc., 100, 841-871, https://doi.org/ 10.1175/BAMS-D-18-0072.1.

Yurkin, M. A., and A. G. Hoekstra, 2011: The discrete-dipoleapproximation code ADDA: Capabilities and known limitations. J. Quant. Spectrosc. Radiat. Transfer, 112, 2234-2247, https://doi.org/10.1016/j.jqsrt.2011.01.031.

Zawadzki, I., E. Jung, and G. Lee, 2010: Snow studies. Part I: A study of natural variability of snow terminal velocity. J. Atmos. Sci., 67, 1591-1604, https://doi.org/10.1175/ 2010JAS3342.1. 